University of Rhode Island

DigitalCommons@URI

Open Access Dissertations

1977

\title{
EFFECT OF CONDITIONAL STIMULUS ON MORPHINE WITHDRAWAL SIGNS IN THE RAT
}

Richard B. Drawbaugh

University of Rhode Island

Follow this and additional works at: https://digitalcommons.uri.edu/oa_diss

\section{Recommended Citation}

Drawbaugh, Richard B., "EFFECT OF CONDITIONAL STIMULUS ON MORPHINE WITHDRAWAL SIGNS IN THE RAT" (1977). Open Access Dissertations. Paper 145.

https://digitalcommons.uri.edu/oa_diss/145

This Dissertation is brought to you for free and open access by DigitalCommons@URI. It has been accepted for inclusion in Open Access Dissertations by an authorized administrator of DigitalCommons@URI. For more information, please contact digitalcommons-group@uri.edu. 
EFFECT OF CONDITIONAL STIMULUS ON MORPHINE WITHDRAWAL SIGNS IN THE RAT

BY

RICHARD B. DRAWBAUGH

A THESIS SUBMITTED IN PARTIAL FULFILLMENT OF THE REQUIREMENTS FOR THE DEGREE OF DOCTOR OF PHILOSOPHY

IN

PHARMACEUTICAL SCIENCES

(Pharmacology \& Toxicology)

UNIVERSITY் OF RHODE ISLAND

1977 
CONDITIONAL STIMULUS EFFECTS ON WITHDRAWAL SIGNS 


\section{DOCTOR OF PHILOSOPHY THESIS}

OF

RICHARD B. DRAWBAUGH

Approved :

Thesis Committee:

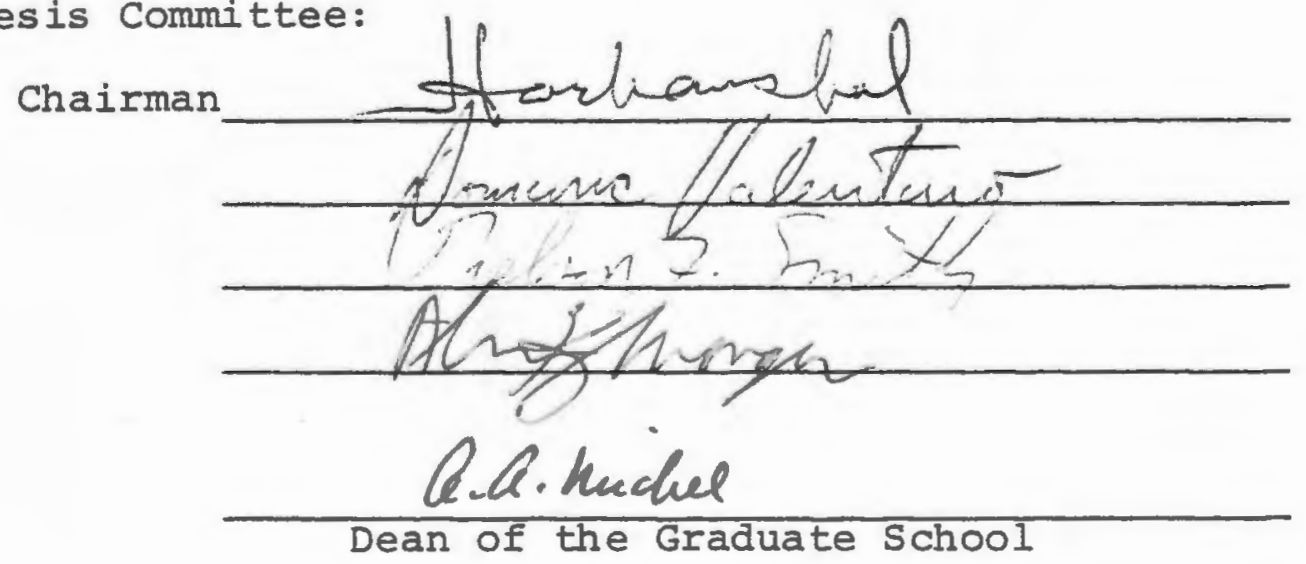

UNIVERSITY OF RHODE ISLAND 


\section{ACKNOWLEDGEMENTS}

The author wishes to express his gratitude to his parents, Mr. \& Mrs. John H. Drawbaugh. Also to his aunt and uncle, Mr. \& Mrs. Richard Shepley and grandmothers Mrs. Pearle Betz and Mrs. Grace Drawbaugh for their inspiration, thoughtulness and financial assistance during the years required for this thesis.

Special thanks are conveyed to Dr. Harbans Lal, his major professor, whose guidance during these experiments and patience with the experimenter were greatly appreciated.

The author wishes to thank the other members of his committee, Drs. Nelson Smith, Dom Valentino and a special thanks to Dr. Alvin Swonger who was extremely helpful throughout the author's graduate education.

The author also wishes to thank his fellow students for their assistance and helpful suggestions during these studies and Mrs. Edith Williams for typing the thesis.

The author is very grateful to the University of Rhode Island and grant DA00418 from the National Institute of Drug Abuse for providing financial assistance during these studies. 
to MY PARENTS

iii 


\section{ABSTRACT}

The present investigation was undertaken to demonstrate the comparisons and contrasts of the conditional stimuli's (CS's) actions with those of morphine in morphine withdrawn rats. The study shows that specific stimuli altered behavioral and physiological withdrawal signs such as: hypothermia, shakes, ptosis, piloerection, writhing and aggression. Also, one stimulus was able to effect two biochemical measures (blood glucose and striatal homovanillic acid) similar to the action of morphine.

Rats were given two equally spaced injections of morphine sulfate paired with different stimuli (bell, drug, oil of anise, saccharin). The stimuli were paired with an injection for 15-25 days. Twenty-four hours after the last morphine injection the appropriate stimulus was presented.

The rats learned to increase their body temperature, reduce wet shakes, increase ptosis, reduce writhing and reduce aggressive responses following the presentation of oil of anise. The bell stimulus only increased temperature. The gustatory stimulus increased temperature and the drug stimuIi had no effect on withdrawal signs. The changes observed were specific only to animals that had the respective stimuli paired with morphine prior to challenge treatment. The duration of the CS in the oil of anise study was important, the onset required a time period of greater than 2 min 
but no more than $30 \mathrm{~min}$ for the maximal effect. When naive animals were exposed to the stimuli, no changes were observed either behaviorally or physiologically. Those animals receiving random CS or no cS during addiction demonstrated no change in observed withdrawal signs when presented the CS $24 \mathrm{hr}$ or $48 \mathrm{hr}$ after the last morphine injection.

In the presence of naloxone, a pure narcotic antagonist, oil of anise-morphine paired animals receiving the CS, $24 \mathrm{hr}$ after the last morphine-CS pairing exhibited no change in withdrawal signs which previously had been changed by the CS. This data implies, indirectly, the release of a morphinelike substance in the production of the cs effects.

In addition to the behavioral and physiological measure brought under stimulus control, two biochemical measures (blood glucose and striatal homovanillic acid) were specifically increased by the CS (oil of anise) in a manner similar to that seen by morphine alone, therefore showing that the conditional responses of morphine addiction are not just behavioral but also involve biochemical systems.

These data indicate that the changes resulting from morphine presentation during withdrawal can be classically conditioned. The responses are of three types - behavioral, biochemical and physiological. 
ACKNOWLEDGEMENTS. • . . . . . . . . . . . . . ii

DEDICATION . . . . . . . . . . . . . . . . . iii

ABSTRACT . . . . . . . . . . . . . . . . . iv

TABLE OF CONTENTS . . . . . . . . . . . . . . . . vi V

LIST OF TABLES. • • • • • • • • • • • • • • • • • viii

INTRODUCTION • • . . . . . . . . . . . . . . . I 1

STIRVEY OF LITERATURE. . . . . . . . . . . . . . . 3

Conditioning Associated with Narcotic Addiction . . 3

A. Behavioral . . . . . . . . . . . 3

B. Biochemical . . . . . . . . . . . . 11

Conditioning Changes of Blood Glucose . . . . . . 12

Behavioral Effects of an Endogenous Morphine-like

Substance . . . . ...... . . . . . . 17

Morphine Effect on Blood Glucose and Homovanillic

Acid Levels . . . . . . . . . . . . . 15

EXPERIMENTAL • . • . . . . . . . . . . . . . 19

Animals . . . . . . . . . . . . . . . 19

Materials . . . . . . . . . . . . . . . 19

Conditioning Procedures . . . . . . . . . . . 20

Temperature Measurements. . . . . . . . . . . 24

Measurement of Withdrawal Signs . . . . . . . . 25

Serum Glucose Measurement . . . . . . . . . . 26

Homovanillic Acid Measurement. . . . . . . . 28

Statistics. . . . . . . . . . . . . 30

RESULTS . . . . . . . . . . . . . . . . . 31

Auditory Stimulus Effects on Selected Withdrawal

Signs Under Different Addiction Schedules . . . . 31

Alteration of Withdrawal Signs by Gustatory and
Intereoceptive Stimuli. . . . . . . . . 38

Olfactory Stimulus Effect on Withdrawal Signs:

Physical, Behavorial and Biochemical. . . . . . 47

Reversal of the Action of Olfactory Stimulus as a

CS by Naloxone. . . . . . . . . . . . 54 


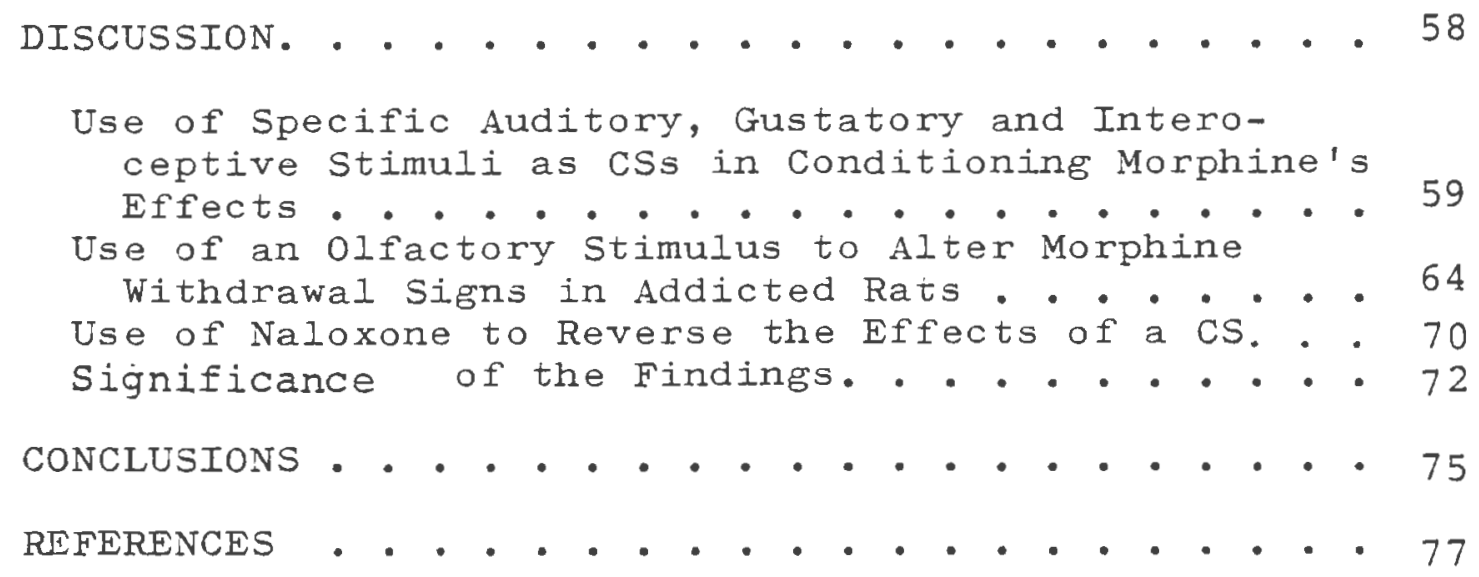




\section{IIST OF TABLES}

TABLE

PAGE

1 Schedules of Chronic Morphine Administration for Conditional Stimulus Experiments. . . 32

2 Effect of the Auditory Stimulus on Withdrawal Signs in Rats Made Morphine Dependent in 15 days to $200 \mathrm{mg} / \mathrm{Kg} /$ day (short-term - low level). . . . . . . . . . . . . 33

3 Effect of the Auditory stimulus on Withdrawal Signs in Rats Made Morphine Dependent in 25 days to $200 \mathrm{mg} / \mathrm{Kg} / \mathrm{day}$ (Iong-term - low level) 36

4 Effect of the Auditory Stimulus on Withdrawal Signs in Rats Made Morphine Dependent in 15 days to $400 \mathrm{mg} / \mathrm{Kg} / \mathrm{day}$ (short-term - high level). . . . . . . . . . . . . 37

5 Effect of the Auditory Stimulus on Withdrawal Signs in Rats Made Morphine Dependent in 25 days to $400 \mathrm{mg} / \mathrm{kg} /$ day (long-term - high level)............... . 39

6 Effect of Gustatory Stimulus (saccharin) on Withdrawal Signs in Rats During the Primary Abstinence Period... . . . . 40

7 Effect of Alcohol (interoceptive) Stimulus on Withdrawal Signs in Rats During the Primary Abstinence Period . . . . . . .

8 Effect of Apomorphine (interoceptive)

Stimulus on Withdrawal Signs in Rats During the Primary Abstinence Period . . . . . .

9 Effect of Pentobarbital (interoceptive) Stimulus on Withdrawal Signs in Rats During the Primary Abstinence Period. . . . . . 45

10 Effect of the Conditional stimuls (oil of anise) Duration on Withdrawal Signs During the Primary Abstinence Period . . . . . . 46

II Effect of the Conditional stimulus (oil of anise) on Rats Made Morphine Dependent for 25 days to $200 \mathrm{mg} / \mathrm{Kg} / \mathrm{day}$ (long-term - low level). . . . . . . . . . . . . . 
12. Effect of Conditional Stimulus (oil of anise) on Morphine Withdrawal Induced Aggression. . 51

13 Effect of the Conditional Stimulus (oil of anise) on blood glucose levels in Naive and Morphine Withdrawn Rats. . . . . . . , 52

14 Effect of the Conditional stimulus (oil of anise) on Striatal Homovanillic Acid Levels in Naive and Morphine Withdrawn Rats . . .

15 Effect of Naloxone Pretreatment on Conditioned Animals Presented the Conditional stimulus During withdrawal. . . . . . . . 55

16 Effect of Naloxone Pretreatment on Blood Glucose Levels in Conditioned Animals Presented the Conditional stimulus During Withdrawal . . . . . . . . . . . 57

17 Summary of Conditioning Experiments. . . . . 76 


\section{INTRODUCTION}

Roffman et al. (1973) and Drawbaugh and Lal (1974) have demonstrated that hyperthermia can be conditioned during morphine abstinence by pairing a neutral stimulus (bell) with morphine administration. The procedures used in these two studies were very similar, requiring between $24-40$ pairings of the bell and morphine. The study by Drawbaugh and Lal (1974) showed that naloxone could block the conditional phenomenon and thus concluded that the conditional stimulus, acting on the brain, may affect the same receptors that morphine affects. Understanding the conditioning factors that are present with morphine administration may be of great importance in treatment of human addicts, at both a behavorial and biochemical level. It should be understood that treating just the physical aspects of drug addiction is not enough, but treatment of the behavioral aspects is also very important in order to increase the cure rate of narcotic addicts.

Conditional responses due to morphine administration were seen as early as 1900 by Faust in dogs injected for 3-4 weeks. Collins and Tatum (1925) reported a conditioned salivary response in dogs after repeated morphine administration. One year later Pavlov reported that an investigator in his lab observed dogs vomiting shortly after the investigator entered the room, a response usually seen following morphine administration. Wikler and Pescor (1970) demonstrated, using the classical conditioning paradigm, that the environment 
associated with abstinence can act as a conditional stimulus and can elicit relapse behavior when the animal is placed in that environment for up to a year following the last morphine injection. In addition, recent evidence indicates that rats can self-administer morphine orally, in their drinking water, and show preference for the conditional stimulus (saccharin) when saccharin is given by itself (Parker et al., 1973). Kumar (1972) paired morphine drinking with an environment and observed that the rats preferred the environment where they received morphine in their drinking water.

The present investigation sought evidence to establish:

1) What is the best schedule of addiction using the bell as a conditional stimulus

2) What is the best kind of conditional stimulus in a rat analog of drug addiction (auditory, gustatory, interceptive or olfactory).

3) Whether naloxone, a drug which is a pure narcotic antagonist (Blumberg and Dayton, 1973), can block other conditional stimuli as it was able to block the auditory CS, therefore, giving further support to the hypothesis that the CS and morphine work by similar mechanisms in the brain.

4) Whether a CS can control not only behavior elicited by morphine, but also biochemical changes usually seen following morphine administration.

5) Whether the conditional phenomenon can be considered as indirect evidence for the stimulus causing its effects by inducing the release of an endogenous morphine-like substance. 


\section{LITERATURE SURVEY}

Conditioning Associated with Narcotic Addiction

A. Behavioral

It has been established by many investigators that some drug reactions can be elicited by environmental stimuli that have been paired a number of times with the drug administration. That is to say that certain drug reactions can and are indeed conditioned. It is well known that one of the first effects of injection of morphine in dogs is to produce nausea and salivation followed by vomiting. Krylov observed in the course of certain serological experiments that following repeated hypodermic injections of morphine into dogs, the symptoms that normally follow injection, nausea, salivation and vomiting, were seen as soon as the experimenter entered the animal quarters. Initially, Krylov observed, after only 5-6 days of morphine injection, that touching the animal could elicit the drug response. In a few additional days, he noted that his entrance into the room could produce the onset of nausea, salivation and vomiting. Thus the greater the number of previous injections of morphine, the fewer the number of stimuli were required to evoke a reaction that simulated that produced by the drug (Pavlov, 1927).

This report, however, was not the first published report of conditioning narcotic effects even though chronologically the work was completed about 1890. Faust (1940) reported that after 3 to 4 weeks of repeated morphine injections, dogs 
were observed to anticipate the injection "as if they felt the need of a new injection.... indeed, in one case the dog would greet me with lively expressions of joy, when I entered the cage with syringe in hand and let the injection be made while he is standing, without being bound in any way." (45, p. 12.$)$

Collins and Tatum (1925) also observed serendipitously the same phenomenon that Krylov and Faust had seen, following only 6-8 injections of morphine. Kleitman and Crisler (1927) replicated the Collins and Tatum experiment by using morphine specifically as a UCS and thereby systematicallyconditioning and extinguishing the salivary reflex observed in dogs.

Crisler (1928) and Kleitman (1929) separately replicated the salivary response observed in dogs which was initially associated with s.c. injection of morphine and later elicited by the needle alone. However, this time both investigators reported the exact number of injections to acquisition of the response and used a specific interval for CS-UCS pairing. Not until 1940 was an experiment (Spragg) carried out which not only looked at number of trials to acquisition, but gave variable doses, observed behavior other than salivary response and used a specific CS (special room).

Not until wikler published an article on conditioning of drug effects in 1948 did a dramatic change in the art of classically conditioning of narcotic effects occur. The conceptual framework used in this study and subsequent studies 
at Lexington is important because it greatly influenced methodologies used in the past two decades. Wikler's studies used techniques similar to Pavlov but was concerned specifically with the role of the central nervous system. He was not able to show a conditional salivary response in decorticate dogs but it could be seen in spinal dogs.

After Wikler's report another period of almost 10 years lapsed before another conditioning experiment was published (Bykov, 1957), and the concern shifted from problems involving classically conditioning morphine effects to questions about the classical conditioning of morphine withdrawal and relapse (Goldberg \& Schuster, 1970; Goldberg et al. 1971;

Parker et al. 1973; Trost, 1973; Wikler \& Pescor, 1967). Utilizing environmental factors that were associated with morphine abstinence, wikler and Pescor demonstrated that rats undergoing withdrawal in their home cage, when placed in that cage 3-6 months later, will show withdrawal signs (wet shakes, writhing). In the same experiment they also demonstrated that animals addicted and withdrawn in their environment will selfadminister a narcotic drug when placed back in that environment for up to 6 months after the last day of narcotic injection. Goldberg and schuster (1970) utilized nalorphine, a narcotic antagonist, to demonstrate conditioned nalorphine induced abstinence changes in morphine dependent monkeys. They observed that after pairing a neutral stimulus (light) with injections, the neutral stimulus alone could elicit a condi- 
tional response (emesis, salivation). These responses were normally seen only following nalorphine injection of morphine dependent animals. Goldberg et al. (1971) demonstrated that monkeys self-administer saline to overcome nalorphine's antagonistic effects if they had previously been given nalorphine and had the opportunity to self-administer morphine to overcome its effects.

Trost (1973) utilized a differential classical conditioning paradigm on morphine dependent rats and showed that the rats which had a specific environmental stimulus paired with each injection did indeed show a completely different kind of behavior when put into that situation where the stimulus or the environmental conditioner previously paired with morphine was again present. He concluded from this differential training, that stimuli paired with morphine withdrawal distress play a more important role in readdiction liability than stimuli associated with withdrawal reduction. In other words the original physiological need for morphine is not present but the associated behaviors may be energized by the expectancy of an oncoming need to a greater extent than by the expectancy of an oncoming relief. Jones and Prada (1973) showed that dogs also relapse to morphine use after 1-6 months of addiction followed by 1-6 months of withdrawal. Following this enforced abstinence, the dogs recommenced selfadministration of morphine whenit again was made available. The results seem to indicate that the post-dependent dogs 
had maintained their dependence on morphine by self-administration. Effects other than those experienced by the initial exposure (such as nausea and vomiting), were responsible for this relapse.

Another group of experiments which bring us up to the present use either rats or primates pretreated with doses of morphine (to $200 \mathrm{mg} / \mathrm{Kg} / \mathrm{day}$ ) aimed at rendering the animal physically dependent, and subsequently testing the conditionability of withdrawal signs precipitated by either narcotic antagonists or sudden cessation of morphine injections. This period began a change in philosophy from conditioning of drug effects to concern of drug dependency as a whole (Iynch et al. 1976).

Beach (1957) began this period of experimentation by reporting that environmental stimuli were able to act as secondary reinforcers for morphine dependent rats. This was later substantiated by Wikler \& Pescor (1967). In Beach's experiment, the rats were given a choice of either the original environment in which they were addicted or a new one whereas in the wikler\& Pescor experiment all were returned to their original environment. The animals preferred the environment in which they had experienced addiction and withdrawal, rather than the neutral one. Thus it was concluded that rats, when abstinent, show a preference for a distinctive environment previously associated repeatedly with withdrawal symptoms (Kumar, 1972; Thompson \& Ostlund, 1965). It can further be 
concluded that environmental stimuli can become secondary reinforcers after repeated pairings with the effects of morphine. There are also antecdotal reports that individual learning may contribute to the maintenance of dependent behavior in humans as well. Another experiment showing development of secondary reinforcers were that of Kumar (1972) utilizing a self-administration technique. They showed that animals given morphine in their drinking water would drink large amounts of quinine if morphine was withdrawn from the water source. They concluded that the bitter taste of quinine was the reason for the large intake. They further concluded that the taste had become a secondary reinforcer. Yet another example of a secondary reinforcer was done by Crowder et al. (1972). Using both classical and operant paradigms, they showed that animals given morphine injections paired with a buzzer would bar-press for the buzzer and a saline infusion. They concluded that the buzzer and a saline infusion had acquired secondary reinforcing properties. It was further concluded that a stimulus can become a secondary reinforcer without being a discriminative stimulus for an operant. Roffman et al. (1973) conducted an experiment using a paradigm somewhat like Crowder et al. (1972) except that a bell was paired with morphine withdrawal and the body temperature of the animal was monitored. They showed that the bell was able to raise the temperature to normal or slightly above normal, suggesting that the animals were able to overcome the hypothermic effect of morphine withdrawal by a preparatory re- 
sponse to the conditional stimulus. They concluded that they were able to condition the effect of morphine; namely, the ability to alter body temperature. This experiment was later replicated by Drawbaugh and Lal (1974). In the latter study, not only were the temperature effects of morphine conditioned but the conditioned response was also blocked by naloxone. This suggested that morphine and the conditional stimulus may be working through the same pathway(s). These experiments could also be considered to suggest that the CS might be working by means of a morphine-like substance (endorphin).

Few systematic studies have been done with humans dealing with conditioning of narcotic effects or withdrawal signs. Levine (1974) reported that two individuals whom he treated at NIMH Clinical Treatment Center, Lexington were true "needle freaks" and found pleasure in "sticking" themselves without heroin. He explained the "needle freak" phenomenon as a form of operant conditioning. The idea that self-injection is operant behavior that leads to the pleasurable experience of intoxication and is therefore positively reinforced. Continued and increased self-injection in the absence of continuous reinforcement can be considered an instance of secondary reinforcement conditioning. Thus there is a behavior (selfinjection) which is directed toward a stimulus with no intrinsic utility that was previously paired with a biologically significant stimulus. Shannon et al. (1976) did a study to see if this "needle freak" phenomenon generalizes to medicinal use of hypodermic needles. They found that no generalization 
was observed and concluded that a chain of behavior is involved with injection of heroin which is not present in a medicinal situation.

$$
\text { o'Brien et al. (1975) attempted to classical condition }
$$
withdrawal signs in man as Goldberg \& Schuster (1967) had earlier done in monkeys. They used naloxone as the UCS, auditory tone and oil of peppermint as the CS with each subject receiving the CS-UCS pairing three-five times per week. On test days a saline injection was given instead of naloxone with the tone and smell. Five of eight patients showed evidence of conditiong of abstinence signs.

Thompson and Pickens (1969) reviewed the conditioning literature and concluded that much of the drug self-administration can be explained by means of operant behavior. They analyzed drug dependence in terms of factors known to control acquisition, maintenance and elimination of the operant responses beliving that these same factors should also control acquisition maintenance and elimination of drug reinforced responses. They felt that looking into these specific areas would lead to a better understanding of the initial development of drug dependence and perhaps contribute to work with the problem of drug addiction. They felt that there are a number of different variables which will effect drug reinforced responses. These variables include antecedent conditions (Kolb, 1962), current stimulus circumstances (Cofer \& Appley, 1964) qualitative and quantitative properties 
of the reinforcing drug as well as a stimuli associated with drug administration (Ausubel, 1963; Weeks \& Collins, 1964). They concluded their review of the literature by stating that drug dependence can at least be partially analyzed by using an operant paradigm and that this approach helps to provide answers to the underlying mechanisms of drug dependence. They at no time concern themselves with classical conditioning. This lack of reference to classical experimentation may be a problem of semantics or a sincere feeling that drug addiction can best be explained and treated as an overt behavioral disorder.

B. Biochemical

Perez-Cruet (1974, 1976) and Lal et al. (1976) are thus far the only labs which have been able to condition biochemical changes due to morphine. Perez-Cruet utilizing a paradigm used in another lab (Roffman, et al. 1973; Drawbaugh \& Lal, 1974) paired a buzzer with a narcotic (methadone) and was able to condition morphine's effects on homovanillic acid (HVA), a dopamine metabolite. Lal and co-workers using oil of anise, paired with morphine, were able to also condition morphine's effects on HVA.

In addition to the use of the gustatory stimulus to control a brain metabolite, Lal and co-workers were able to also condition blood glucose levels. This same lab earlier (Roffman and Lal, 1973) was able to condition biochemical effects produced by pentobarbital, suggesting that not only overt behavior due to a drug are able to be conditioned, but biochemical effects also. 
Conditioning Changes of Blood Glucose

The amount of glucose in the blood of animals is regulated by a feedback system (homeostatic). The importance of this system can be seen in the fact that small deviations of glucose levels are suggestive of serious clinical diseases. An increase of fasting glucose was a sign of diabetes mellitus, and a decrease of fasting glucose is a sign of hypoglycemia. The level of blood glucose is especially important because the brain, unlike the majority of other tissue, is not able to obtain energy from lipids and proteins and thus relies heavily on glucose. Therefore, if glucose levels get too low, the brain cannot function normally and if this continues for a long enough time, coma and death may ensue. A minimal level of glucose in the brain is imperative.

The level of blood glucose has been associated with certain levels of behavior. It is well-documented that the central nervous system is very sensitive to alterations in glucose levels. Changes of glucose levels at specific brain sites causes changes of electrical activity at both single unit and gross potential levels (Anand et al. 1964; Brown, 1969 ; Oomura et al. 1964; Oomura et al. 1969). Also, such changes cause reflex homeostatic alterations of peripheral glucose levels (i.e. adrenals, liver and pancreas) (Muller et al. 1973; Sakata et al. 1963; Szabo \& Szabo, 1972), along with changes in feeding behavior (Balagura and Kanner, 1971; Miselis \& Epstein, 1970). These types of changes have been 
utilized as reinforcers in learning experimentation (Chambers 1956a,1956b). There are other behaviors which glucose levels can be correlated with such as: eating, stress, exercise and arousal. Simply, the amount of glucose in the blood covaries with many different behaviors and has clinical importance. The survey to follow summarizes the experiments in which blood glucose is brought under stimulus control.

The majority of reports on conditioned glycemic response use insulin as the unconditioned stimulus (UCS). Typically, the administration of insulin is repeatedly paired with a neutral stimulus which does not affect blood glucose levels. After a number of days of pairings, the stimulus alone has the ability to elicit a change in blood glucose. If the change is an increase of glucose, it is called hyperglycemia; if a decrease, hypoglycemia.

A number of investigators in the Soviet union performed research on human subjects (schizophrenics and diabetics) and observed conditional responses following neutral stimulus pairing with insulin (Lichko, 1959; Zakharov, 1960; Leites \& Pavlov, 1954). The neutral stimulus was able to change (decrease) blood glucose levels from 12 to $50 \mathrm{mg} \%$ depending upon the laboratory.

Dogs have been the next most frequent choice as subjects for conditioned glucose response experiments. In these experiments, the presentation of insulin was paired with an auditory stimulus, the stimulus was later able to decrease blood glucose levels with or without a saline injection 
(Savchenko, 1940; Leites and Pavlov, 1954; Alvarez-Buyl la and Carrasco-Zanini, 1960).

The remainder of experiments employing insulin as the unconditioned stimulus used rats as subjects. Woods, Makous and Hutton (1968) reported that rats who had repeated pairing of stimulus (auditory) with insulin, when given auditory stimulus + saline, a $12 \mathrm{mg} \frac{\circ}{3}$ change was observed. The same laboratory under the direction of Stephen woods completed a number of additional experiments (Hutton et al., 1970, Woods et al. 1969; Woods and Shogren, 1972) showing an average conditional change in blood gluocse of $25 \mathrm{mg} \%$. It must be noted that in all the experiments demonstrating conditioned hypoglycemia, the conditioned response was smaller than or equal to the unconditioned response.

The duration of the conditioned reponse was from 15 to $30 \mathrm{~min}$ and it declines rapidy thereafter (Alvarez-Buyalla et al. 1960; Woods et al., 1969). Leiters and Pavlov (1954) observed a biphasic response to conditioning procedures. For about the first 30 minutes a hypoglycemic response occurred followed by hyperglycemia. This fact is extremely important and should be noted by investigators unable to obtain conditional changes.

The conditioned response is a function of the number of conditioning trials. The response is able to develop over a minimal number of trials, most experimenters reporting from two to five trials are necessary (Leites \& Pavlov, 1954, woods et al, 1969). It has also been shown that too many 
trials cause the magnitude of the response to lessen and may even invert and get a conditioning of hyperglycemia instead of hypoglycemia (Leites and Paviov, 1954).

Conditioning of hypoglycemia extinguishes rapidly, two to five trials (Leites \& Paviov, 1954; woods et al., 1969). Spontaneous recovery has been noted in rat experiments, but the stimulus effect elicited is very small and only after one week since the last test trial.

The proposed mechanism to explain the above-mentioned experiments is as follows: When insulin is administered to an animal paired with a particular stimulus or set of stimuIi, the response that follows of that animal to the same stimulus but without insulin administration is a decrease of blood glucose called conditioned hypoglycemia. The conditioned response follows properties of a classically conditioned response, and the mechanism that causes this response appears to be CNS-mediated release of pancreatic insulin.

Morphine Effect on Blood Glucose and Homovanillic Acid Levels

Morphine injected into dog (Ross, 1918; Pierce and Plant, 1928), cat (Dey et al., 1975; Feldberg and Shaligman, 1972; Borison, et al., 1962), rabbit (Araki, 1891; Sable-Amplis, 1972), mouse (Sable-Amplis, 1972) and rat (Sable-Amplis, 1972) caused hyperglycemia, the intensity of which varies according to the species and the dose. Except for Pierce and Plant (1928) and Sable-Amplis (1972) the above studies were limited to the acute effects of morphine on blood glucose levels. 
Pierce and Plant addicted dogs from 50-280 days with a terminal dose ranging from 40-220 $\mathrm{mg} / \mathrm{Kg}$. However, even with these large variations in dose and duration of addiction the results for all animals were similar. Acute dose of morphine caused a pronounced hyperglycemia, however, within 10 days of injections the effect disappeared (tolerance developed). Upon withdrawal some time between the 2 nd and 5 th day, a transient period of hyperglycemia was observed.

Sable-Amplis gave mice, rats and rabbits doses of morphine ranging from $10-40 \mathrm{mg} / \mathrm{Kg}$ for a period of up to 15 days. In all cases tolerance developed within 7 days, 3 days for the mouse. Gradual increases of $10 \mathrm{mg} / \mathrm{Kg}$ injection was not enough to cause the increased blood glucose levels. Thus, suggesting that a rapid tolerance deveiops to glucose changes following morphine on all species mentioned.

If an extract (brain) of tolerant mice is injected into naive mice the naive animals when injected with morphine will already possess altered metabolic effects due to the extract and show no change due to the morphine (Sable-Amplis, 1972). In rabbits, altered metabolism of glycogens exists for 3 weeks after withdrawal from morphine, thus the effects of morphine on glucose in vivo is dramatic and long-lasting in many types of animals.

Homovanillic acid (HVA) levels have not been studied to any great extent following morphine administration. Therefore, the number of studies correlating HVA with morphine's effect on behavior are even fewer. 
Morphine has been shown to increase HVA content of striatum in several animal species (Ahtee and Kaariainen, 1973; Fukui and Takagi, 1972; Kuschinsky and Hornykiewicz, 1972; Sasame et al. 1972; Perez-Cruet, 1976). However, only Kaariainen and Ahtee (1976) have attempted to correlate the change in HVA levels with behavior (analgesia) utilizing the hot plate technique.

They found some degree of correlation of morphine and methadone increases in HVA with peak analgesic action. They concluded that morphine though it does not act primarily on dopaminergic neuronal systems, it does affect striatal dopamine areas. This suggests that at least one and possibly other alterations in behavior due to morphine may be associated with changes in HVA levels.

Behavioral Effects of an Endogenous Morphine-Like Substance The evidence for the presence of an endogenous ligand of the opiate receptor is now so convicing that it is important to compare known behaviorial properties of narcotics with the behavorial activity of this substance.

The substance is called endorphin and it has been shown to block electrically evoked contractions of the mouse vas deferens and the guinea pig ileum and inhibit the stereospecific receptor binding of the opiate antagonist (naloxone) in brain homogenates (Hughes et al. 1975). However, only very recently have any overt behavorial changes been shown by administration of endorphin to intact animals. 
King and co-workers (1976) showed that a partially purified enkephalin given to mice intracerebroventricularly caused straub tail and piloerection. Morphine, $15 \mathrm{ug}$, given in the same manner caused a similar response. The effects of the opiate-like substance were immediately abolished by naloxone given intravenously. Also Belluzzi and co-workers (1976) showed that giving enkephalin in the same manner as King caused analgesia which could be reversed by giving naloxone subcutaneously and which could not be established again by another injection of enkephalin. Only after naloxone wore off could enkephalin again produce analgesia. Thus direct evidence does exist for behavorial properties of this morphinelike substance. 
EXPERIMENTAL

Animals

Male hooded rats of the Long-Evans strain, random-bred, weighing 250-300 grams at the beginning of the experiments, were obtained from Charles River Breeding Farms (Canadian Breeding Farm and Laboratories, Inc.), Wilmington, Massachusetts. All animals were experimentally naive for this study. The rats were housed in individual cages in a room maintained at $21-23^{\circ} \mathrm{C}$ with the lights alternating on a 12-hour darklight cycle. Food (Wayne Lab Blox) and water were available ad libitum except dirirs; the injections and during the physiological measurements.

\section{Materials}

1. Chemicals and Drugs

Analytical reagent grade chemicals or equivalent were used throughout this study. The co-factors, adenosine triphosphate (ATP), nicotinamide adenine dinucleotide phosphate (NADP), hexokinase (yeast), and glucose-6-phosphate dehydrogenase (G-6-PD) were obtained from Sigma Chemical, St. Louis, Missouri.

N-butryl-acetate was obtained from Aldrich Chemical Co., St. Louis, Missouri,

Morphine sulfate was obtained from Merck \& Co., West Point, Pa. Naloxone hydrochloride was from Endo Laboratories, Inc., Garden City, New York. Apomorphine hydrochloride was obtained from Mallinckrodt Chemical Works, st. Louis, Mo. Pentobarbital sodium was obtained from Abbott Laboratories, 
Chicago, Ill. Ethanol (95\%) was obtained from U.S. Distillers. Saccharin was obtained from McKesson, Bridgeport, Conn. Oil of anise was obtained from Merck, New Jersey.

All drugs were dissolved in distilled water. Doses are presented in terms of salts. The volume of each injection never exceeded $0.7 \mathrm{cc}$, and all saline injections were equal in volume to their corresponding drug treatment injections. 2. Reagents

a. Perchloric acid $(0.4 \mathrm{~N}): 34.4 \mathrm{ml}$ of concentrated perchloric acid (70\%, Mallinckrodt Chemical Works) was diluted to one liter.

b. Tris buffer $(.05 \mathrm{M}): 4 \mathrm{gm}$ of tris-(hydroxymethy 1 ) aminomethane (Calbiochem) was dissolved in $500 \mathrm{ml}$ of deionized glass distilled water. The pH of tris solution was then adjusted to 8.5 by adding $0.5 \mathrm{M} \mathrm{HCl}$ (J. T. Baker). The final volume was brought to 1 liter by deionized glass distilled water.

$$
\text { c. L-cysteine (0.1\%):100 } \mathrm{mg} \text { of L-cysteine (Aldrich }
$$
Chemical Co.) was dissolved in $100 \mathrm{ml}$ of deionized glass distilled water.

d. Potassium ferricyanide $(0.02 \%): 20 \mathrm{mg}$ of potassium (Aldrich Chemical Co.) was dissolved in $100 \mathrm{ml}$ of deionized glass distilled water.

Conditioning Procedures

a. Auditory: Conditioning consisted of giving an injection of morphine sulfate paired with a bell sound (78 $\mathrm{db}$ 
$20 \mathrm{KHZ}$ SPI (sound pressure level) measured one meter from the be11) twice daily at 0830 and 2030 according to the four different schedules appearing in Table I. The injections of morphine were spaced 12 hours apart beginning with $10 \mathrm{mg} / \mathrm{kg} /$ injection, and were increased by $10 \mathrm{mg} / \mathrm{kg}$ every third injection until $100 \mathrm{mg} / \mathrm{kg} /$ injection $(200 \mathrm{mg} / \mathrm{kg} /$ injection) or $200 \mathrm{mg} / \mathrm{kg} / \mathrm{day}(400 \mathrm{mg} / \mathrm{kg} / \mathrm{day})$ was reached (Table I). The rats were maintained at this dose for 2-15 days and then withdrawn.

The procedure for injection during the morning session was as follows: each animal was taken out of its home cage (one animal injected at a time), placed in a plastic container and taken to a sound attenuated and temperature controlled room $\left(21^{\circ} \mathrm{C} \pm 2\right) \quad 40$ feet from the room where the animals were housed. Immediately after entering the chamber the animal was removed from the plastic container and placed into a singlepan balance to be weighed and then returned to the plastic container. The bell was turned on and after 45 seconds the animal was picked up and securely held, one hind leg and the head, so as to prevent the animal from movement and the injection was given. Then the animal was again returned to the plastic container, and after a total of 60 seconds had elpased, the bell was turned off. The rat was then immediately returned to his individual cage. Each day the order of animals going through this procedure was changed.

The identical procedure was followed during the evening session with the exception that the animal's weight was not taken at that time. 
b. Taste: Conditioning consisted of giving an injection of morphine sulfate paired with saccharin (0.1\%) twice daily at 0830 and 2030 (Table 2). The injections of morphine were spaced 12 hours apart beginning with $10 \mathrm{mg} / \mathrm{kg}$ and were increased by $10 \mathrm{mg} / \mathrm{kg}$ every third injection until $100 \mathrm{mg} / \mathrm{kg} /$ injection or $200 \mathrm{mg} / \mathrm{kg} /$ day was reached. The rats were maintained at this dose for 15 days and then withdrawn.

The procedure for injection during the morning session was as follows: each animal was taken out of its home cage (one animal injected at a time), placed in a plastic container and taken to a single-pan balance to be weighed and then returned to the plastic container. The animal was then removed from the container, an intragastric tube (attached to a one ml syringe filled with $0.1 \%$ saccharin) was inserted into its mouth and $0.5 \mathrm{ml}$ was slowly infused for 30 seconds. At this time the morphine injection was given by the same method discussed above. The animal was then placed back in its home cage. Each day the order of animals going through this procedure was changed.

The identical procedure was followed during the evening session with the exception that the animal's weight was not taken at that time.

c. Intereoceptive (drug): Conditioning consisted of giving an injection of morphine sulfate paired with either pentobarbital (10 mg/kg/i.p.), apomorphine ( $1.25 \mathrm{mg} / \mathrm{kg} / \mathrm{i} . \mathrm{p}$. ) or alcohol ( $1 \mathrm{gm} / \mathrm{kg} / \mathrm{I.G.}$ ) twice daily at 0830 and 2030 . The injections of morphine were given as described in Table 1 . 
The procedure for injection during the morning session was as follows: each animal was taken out of its home cage (one animal injected at a time), placed in a plastic container and taken to a single-pan balance to be weighed and then returned to the plastic container. The animal was again removed from the container and injected with one of the three abovementioned drugs. The animal was then placed back in its home cage for a specific period of time (pentobarbital and apomorphine $10 \mathrm{~min}$, alcohol $5 \mathrm{~min}$ ). After waiting a designated period of time the animal was taken from its home cage and given an injection of morphine by the same method discussed previously. The rat was placed back in its home cage immediately after being injected.

The identical procedure was followed during the evening session with the exception that the animal's weight was not taken at that time.

d. Olfactory (oil of anise): Conditioning consisted of giving an injection of morphine sulfate paired with oil of anise smell twice daily at 0830 and 2030 . The injections of morphine were given as described previously (Table 2).

The procedure for injection during the morning session was as follows: each animal was taken out of its cage, placed in a plastic container (5/container) and taken to a single-pan balance to be weighed (each animal separately) and then returned to the plastic container. The container was then taken to a room, maintained at a constant temperature ( $21 \pm C$ 1), where 
they were placed (5/jar) into a plexiglass jar $(30.5 \mathrm{~cm} \times 30.5 \mathrm{~cm})$. The jar contained a $10 \mathrm{~cm}$ plexiglass cube filled with gauze which had 12 drops of anise oil. After the animals were placed in the jar a perforated stainless steel cover was placed over the jar to prevent the animals from escaping. Five minutes after the animals were placed in the jar each was removed and injected with an appropriate dose of morphine. The animals were returned to the jar after the injections for the duration of the $30 \mathrm{~min}$ pairing session. At 30 min the animals were placed back into the plastic container and returned to their home cages.

The identical procedure was followed during the evening session with the exception that the animal's weight was not taken at that time.

\section{Temperature Measurements}

Al1 temperature measurements were taken at designated times using a digital thermistor thermometer (Digitec Model 8500-2 by United Systems Corporation, Dayton, Ohio). The rectal probe (Model 402, Yellow Springs Instrument Co., Maryland) was inserted $5 \mathrm{~cm}$ (Myers, 1971) into the rectum for one min (Lomax, 1970). Each animal had his temperature taken immediately before and $30 \mathrm{~min}$ after the appropriate conditioning paradigm at 0830 on two successive days preceding withdrawal. These four insertions of the probe allowed the animals to adjust to the procedure. Also, the animals were handled very carefully during both the adjustment trials 
mentioned above and during the experimental measurements. One hand was placed on the back of the animal about midline, the thumb and index finger holding the tail with a minimal amount of pressure (just enough to keep the animal still). The other hand inserted the probe (coated with mineral oil) $5 \mathrm{~cm}$ and held it in place for one min.

Measurement of Withdrawal symptoms

Rats dependent on morphine were removed from their home cages and placed in a novel environment (Wikler and Pescor, 1967) to observe their behavior. The animals were observed for $30 \mathrm{~min}$ prior to test treatment and at $30 \mathrm{~min}$ following treatment. The following bits of behavior (withdrawal symptoms) were observed:

a. Shakes - These were movements of the head and/or body which resemble the behavior an animal exhibits when water is poured over him. The frequency of shakes was tabulated during the $30 \mathrm{~min}$ session.

b. Ptosis - This condition was present when the animal's eyelids were drooping but not closed tightly and he was capable of movement. The animal moves periodically, and this state is distinguishable from sleep. The amount of time spent in this state was measured by elapsed timers and cumulated over the 30 min observation period.

c. Writhing - This consisted of dragging the abdomen on the floor of the observation cage or arching of the back, neither of which was accompanied by yawning. Total number of writhings were measured and cumulated during the $30 \mathrm{~min}$ observation period. 
d. Piloerection - This symptom was scored when the rat's fur stood out from the body. If no piloerection was observed a score of 0 was given. Questionable piloerection was given a score of 1 . If the hair stood out at about $45^{\circ}$ then a score of 2 was given. The score of 3 was given if the animal's hair was perpendicular to his body. This measurement was made after the animal had time to groom following placement into the observation chamber. This was done so as not to report ruffed fur that might have resulted from handing.

Changes in body weight and temperature were monitored just prior to placing the animals in the observation cages.

All of the measurements were made at 0,24 and 48 hours following the last morphine injection. These observations were always made between 0800 and 1100 hours.

e. Aggression - This was measured only in the oil of anise conditioned animals and the control groups for that experiment. This was done by observing (while the animals were in the plexiglass jars for $30 \mathrm{~min}$ ) for vocalizations, rearing and attacking. Since no sophisticated equipment was used, aggression was considered present if vocalizations were heard and at least 20 attacks were seen accompanied by rearing behavior during the first $15 \mathrm{~min}$ of the test period. Thus aggression was either present or absent for each group tested.

\section{Serum Glucose}

The glucose level in the blood was evaluated by measuring the conversion of glucose to glucose-6-phosphate by 
adenosine triphosphate in the presence of hexokinase, coupled with the subsequent reduction of NADP to NADPH.

$$
\begin{aligned}
& \text { Glucose + ATP } \frac{\text { hexokinase }}{\mathrm{G}-6-\mathrm{PD}} \mathrm{G}-6-\mathrm{P}+\mathrm{ADP} \\
& \mathrm{G}-6-\mathrm{P}+\mathrm{NADP} 6-\mathrm{PG}+\mathrm{NADPH}
\end{aligned}
$$

Abbrevations:

$$
\begin{aligned}
& \text { ADP - adenosine diphosphate } \\
& \text { ATP - adenosine triphosphate } \\
& \text { G-6-P - glucose-6-phosphate } \\
& \text { G-6-PD - glucose-6-phosphate dehydrogenase } \\
& \text { NADP - nicotinamide adenine dinucleotide phosphate } \\
& \text { NADPH - nicotinamide adenine dinucleotide phosphate, } \\
& \text { reduced form. }
\end{aligned}
$$

Each animal was individually placed in a plexiglass restraint with only its tail outside of the restraint. The tail was submerged into a water bath $(55$ C) for 45 seconds to dilate the tail vein. Upon removal from the bath the tail was wiped dry and $2 \mathrm{~mm}$ was cut, using surgical scissors. Blood was collected in a plastic centrifuge tube which contained. $1 \mathrm{ml}$ sodium fluoroacetate (anticoagulant). After blood was obtained from the animals it was taken to a clinical centrifuge and spun at 4000 rpm for $10 \mathrm{~min}$. Following centrifugation serum was pipetted from each sample and placed into $\operatorname{small}(5 \mathrm{ml})$ serum vials.

The serum was added $(0.02 \mathrm{ml})$ to a cuvet which contained $3.0 \mathrm{ml}$ of $\mathrm{mix}$ (ATP .005 M, NADP .0002 M, Mg .005M, 
hexokinase 0.8 units/ml, G-6-PD 0.4 units/ml) and assayed spectrophotometrically (absorbance at $340 \mathrm{~nm}$ ) (Barthelmai and Czok, 1962). The initial absorbance was taken prior to addition of the sample (mix alone) and the final absorbance was measured 5 min after the sample was added to the cuvet (mix and serum). Serum blank was prepared by adaing .02 ml serum to $3 \mathrm{ml} / 0.85 \% \mathrm{NaCl}$ in a cuvet and its absorbance read at $340 \mathrm{~nm}$ in a Gilford model no. 2400 spectrophotometer. The concentration of glucose in the experimental samples was determined by the following:

Absorbance=Final Absorbance-Initial AbsorbanceSerum blank absorbance. Serum glucose (mg/100 $\mathrm{ml}$ )=Absorbance X 440 .

The 440 is a factor derived by taking into account the volume of liquid in cuvet, weight of 1 micromole of glucose, absorbance at $340 \mathrm{~nm}$ of a solution containing 1 micromole of $\mathrm{NADPH} / \mathrm{ml}$ and volume of specimen. The calculated concentration was expressed as mg of glucose.

Homovanilic Acid

Homovanillic acid (HVA) was evaluated by measuring the levels in corpus striata spectrofluorometrically. The animals were allowed food and water ad libitum prior to being sacrificed by decapitation. The brains were rapidly removed from the cranium and placed in ice. The lateral ventricles were opened to expose the corpus striatum which was removed from each side and pooled. All of the above procedure was carried 
out on ice using ice-chilled surgical apparatus. The striata were weighed and pooled with striata of another animal and homogenized in $6 \mathrm{ml}$ of $0.4 \mathrm{~N}$ perchloric acid. The homogenate was transferred to a $15 \mathrm{ml}$ plastic centrifuge tube and centrifuged at $10,000 \mathrm{~g}$ at $0^{\circ} \mathrm{C}$ for $15 \mathrm{~min}$ in a servall $\mathrm{RC} 2 \mathrm{~B}$ refrigerated centrifuge.

The supernatant from each centrifuge tube was transferred into a large $50 \mathrm{ml}$ capable tube. The supernatant was then saturated with $\mathrm{NaCl}(2.5 \mathrm{~g} / \mathrm{sample}) . \mathrm{N}$-butylacetate $(10 \mathrm{ml})$ was added to the samples and the mixture shaken for $30 \mathrm{~min}$. Following the $30 \mathrm{~min}$ of shaking each sample was centriguged in a clinical centrifuge at $2000 \mathrm{~g}$ for $5 \mathrm{~min}$. Then $9 \mathrm{ml}$ of the butylacetate layer was transferred to another $30 \mathrm{ml}$ capable tube containing $3 \mathrm{ml}$ of $0.05 \mathrm{M}$ tris buffer, shaken for $20 \mathrm{~min}$ and again centrifuged for $5 \mathrm{~min}$ in a clinical centrifuge. A $1.5 \mathrm{ml}$ tris buffer extract was transferred to a test tube and assayed spectrophotometrically (Anden et al., 1962). To the test tube was added $0.5 \mathrm{ml}$ of glass distilled water, $1.5 \mathrm{ml}$ of $5 \mathrm{~N}$ ammonium hydroxide and $0.2 \mathrm{ml}$ of $0.02 \%$ potassium ferricyanide. Exactly $4 \mathrm{~min}$ later was added $0.2 \mathrm{ml}$ of 0.18 L-cysteine solution, the concentration of HVA was estimated by reading the samples at $425 \mathrm{~nm}$ while activating at $320 \mathrm{~nm}$ in an Aminco-Bowman Spectrofluorometer. The concentration of HVA in the experimental samples was determined by comparing the fluorescence with the known concentration of a standard HVA solution. The calculated concentration was expressed as nanograms of HVA per gram of tissue. 
Statistics

The following statistical procedures were used in this study when the significance of a result was not clear. Student's "t" tests were used for determining the significance of a difference between two correlated means (i.e., pretreatment and post-treatment temperatures). Both independent and dependent " $t$ " tests were used as described in Goldstein (1964).

Where aata required a comparison of an experimental group with a number of control groups, chi-square test was used according to Goldstein (1964). 


\section{RESULTS}

The results of this investigation are divided into four sections: effects of auditory stimulus on withdrawal signs using different schedules of addiction; alteration of withdrawal signs by gustatory and intereoceptive stimuli; effects of olfactory stimulus on withdrawal signs; and reversal of the effects of olfactory CS by a narcotic antagonist.

A. Auditory Stimulus Effects on Selected Withdrawal signs Under Different Addiction Schedules

Previous work by this investigator established a bellsound as an auditory conditional stimulus (CS) capable of reversing morphine withdrawal hypothermia (Drawbaugh and Lal; 1974, 1976). It was then decided to determine if other withdrawal signs could be altered by pairing the bell sound with morphine administration. Changes in temperature were measured along with five additional withdrawal signs: weight, shakes, ptosis, piloerection, and writhing. The rats were addicted by injecting morphine paired with bell as previously described. Following addiction they were withdrawn and exposed to either the bell sound or nothing every $24 \mathrm{hr}$ and their withdrawal signs were measured at 24 and 48 hr after their last morphinebell pairing. Other animals who received morphine alone during addiction received either the bell or nothing following the same procedure mentioned above. 
Table 1

Schedules of Chronic Morphine Administration for Conditional Stimulus Experiment

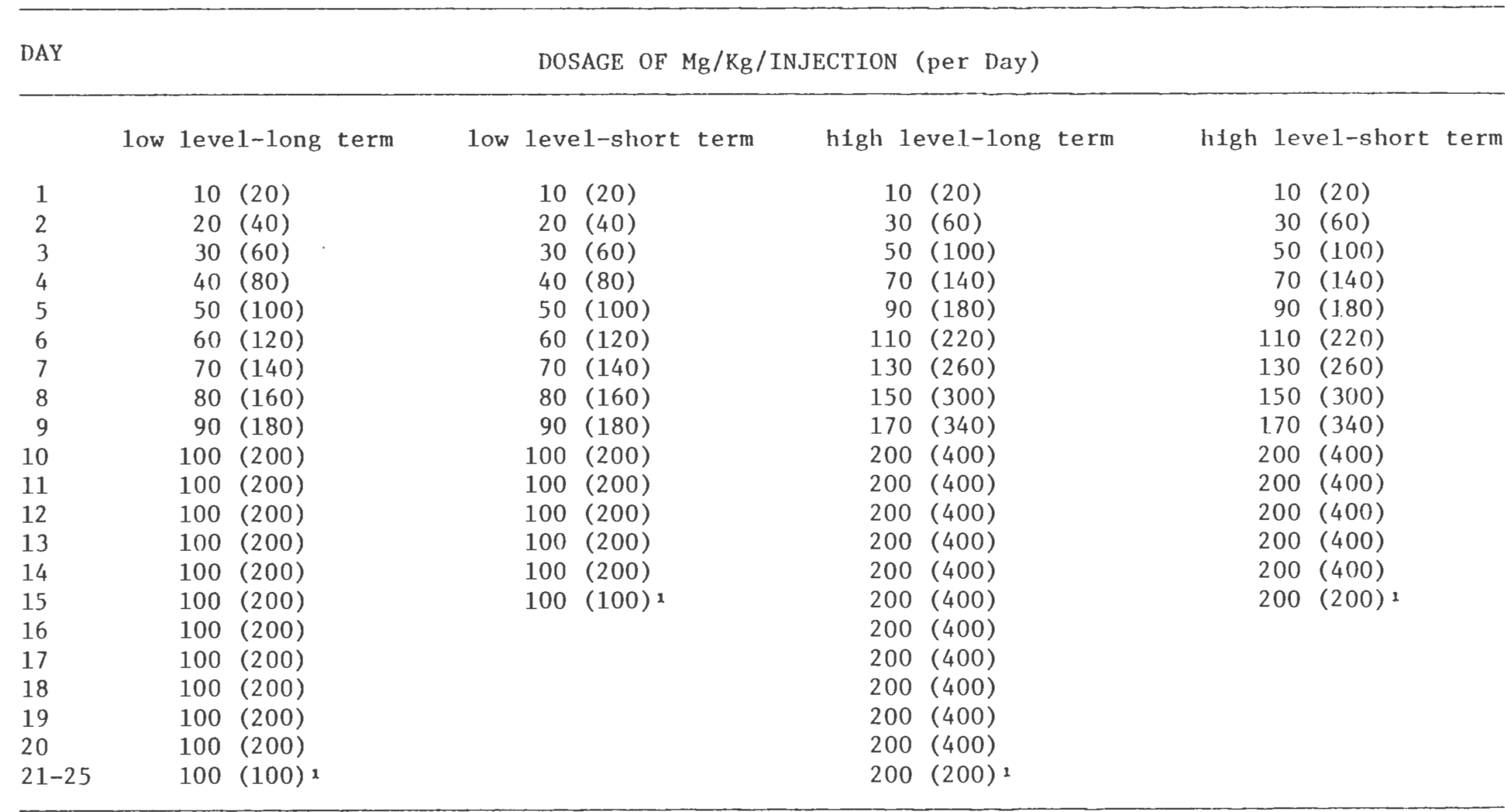

${ }^{1}$ Last injection of sequence (0830). 
Table 2

Effect of the Auditory Stimulus on Withdrawa1 Signs in Rats, Short term (15 days) Low leve1 (200 mg/kg/day) of addiction

\begin{tabular}{|c|c|c|c|c|c|c|c|c|}
\hline \multirow{2}{*}{$\begin{array}{l}\text { Treatment } \\
\text { during } \\
\text { Addiction }\end{array}$} & \multirow{2}{*}{$\begin{array}{l}\text { Treatment } \\
\text { during } \\
\text { Withdrawal } 2\end{array}$} & \multirow[b]{2}{*}{$\mathrm{N}^{3}$} & \multicolumn{6}{|c|}{ Withdrawa1 Signs $^{4}$ (mean \pm s.e.) } \\
\hline & & & Weight $^{5}$ & Temperature $^{6}$ & Shakes & Ptosis ${ }^{7}$ & Piloerection & ${ }^{8}$ Writhing \\
\hline & & & & & & 24 HOURS OF & WITHDRAWAL & \\
\hline Morphine & none & 28 & $\begin{array}{l}301.4 \pm 4.2 \\
296.7 \pm 5.0 \\
-4.7 \pm 1.3\end{array}$ & $\begin{array}{l}37.25 \pm .03 \\
37.15 \pm .05 \\
-0.10 \pm .06\end{array}$ & $2.71 \pm 0.43$ & $37 \pm 18$ & $25 / 28$ & $0.68 \pm 0.26$ \\
\hline Morphine & be11 & 10 & $\begin{array}{r}302.2 \pm 6.8 \\
297.2 \pm 8.1 \\
-4.9 \pm 2.0\end{array}$ & $\begin{array}{l}37.28 \pm .05 \\
37.27 \pm .04 \\
-0.01 \pm .04\end{array}$ & $4.40 \pm 1.89$ & 0 & $10 / 10$ & $0.40 \pm 0.16$ \\
\hline $\begin{array}{c}\text { Morphine } \\
+ \\
\text { Be11 }\end{array}$ & none & 9 & $\begin{array}{l}301.0 \pm 6.3 \\
298.9 \pm 6.6 \\
-2.1 \pm 1.0\end{array}$ & $\begin{array}{l}37.26 \pm .07 \\
37.31 \pm .06 \\
+0.05 \pm .07\end{array}$ & $2.67 \pm 0.41$ & 0 & $9 / 9$ & 0 \\
\hline $\begin{array}{c}\text { Morphine } \\
+ \\
\text { Bel1 }\end{array}$ & be11 & 10 & $\begin{array}{r}308.5 \pm 6.4 \\
303.7 \pm 6.9 \\
-4.8 \pm 0.9\end{array}$ & $\begin{array}{l}37.23 \pm .04 \\
38.06 \pm .09 \\
+0.82 \pm .099\end{array}$ & $3.30 \pm 0.78$ & 0 & $10 / 10$ & $0.40 \pm 0.16$ \\
\hline
\end{tabular}

48 HOURS OF WITHDRAWAL

\begin{tabular}{|c|c|c|c|c|c|c|c|c|c|}
\hline Morphine & none & 28 & $\begin{array}{l}276.4 \pm 4.3 \\
-25.1 \pm 1.9\end{array}$ & $\begin{array}{r}37.24 \pm .04 \\
37.16 \pm .05 \\
-0.08 \pm .05\end{array}$ & $5.50 \pm 0.60$ & $5 \pm 5$ & 28 & $/ 28$ & $0.86 \pm 0.24$ \\
\hline Morphine & be 11 & 10 & $\begin{array}{l}275.4 \pm 6.5 \\
-26.8 \pm 2.4\end{array}$ & $\begin{array}{l}37.24 \pm .06 \\
37.25 \pm .05 \\
+0.02 \pm .04\end{array}$ & $4.60 \pm 1.58$ & 0 & 10 & $/ 10$ & $1.10 \pm 0.43$ \\
\hline $\begin{array}{c}\text { Morphine } \\
+ \\
\text { Be11 }\end{array}$ & none & 9 & $\begin{array}{l}275.4+6.6 \\
-25.6+1.8\end{array}$ & $\begin{array}{l}37.18 \pm .07 \\
37.23 \pm .05 \\
+0.05 \pm .05\end{array}$ & $5.56 \pm 1.16$ & $18 \pm 14$ & 9 & $/ 9$ & $0.56 \pm 0.44$ \\
\hline
\end{tabular}


Table 2 (continued)

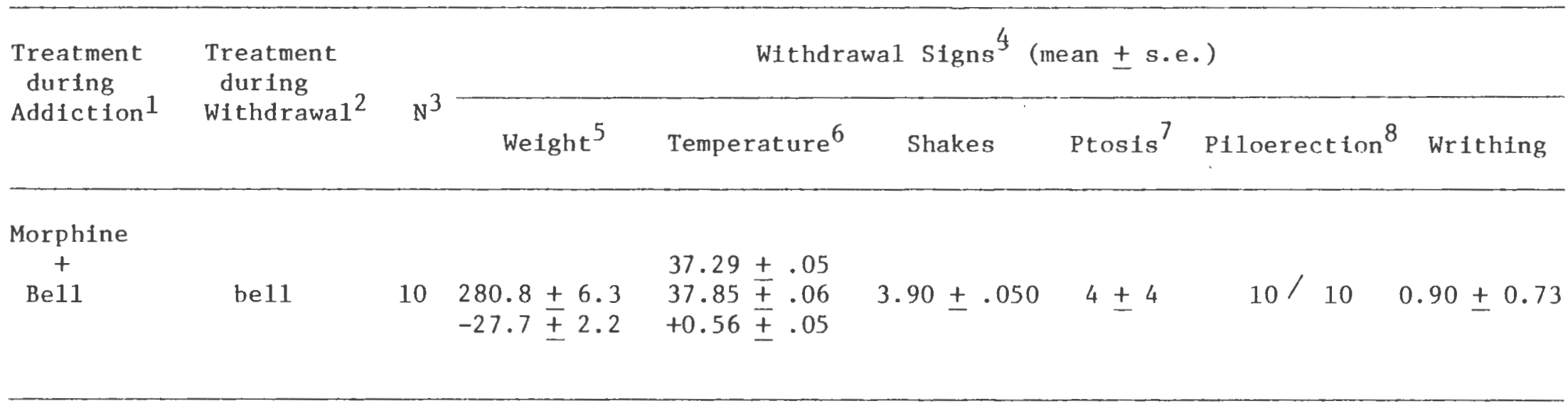

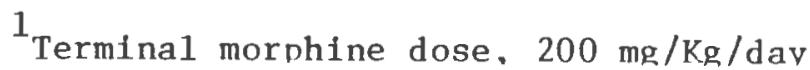

2presented $30 \mathrm{~min}$ prior to withdrawal measurements.

$3_{\mathrm{Number}}$ of animals in each group.

${ }_{5}^{4}$ Signs measured for $30 \mathrm{~min}$. excent for weight and temperature.

${ }^{5}$ Change is comparing zero time with 24 and $48 \mathrm{hr}$ withdrawal measure.

${ }^{6}$ Temperature taken prior to and $30 \mathrm{~min}$ after treatment during withdrawa1.

7 Measured in seconds (duration) during $30 \mathrm{~min}$. observation period.

8 Number of animals showing symptom out of total number observed in each group.

${ }^{9} \mathrm{P}$ value .01 using Student's t-test (each animal used as own contro1) 
The data presented in Table 2 demonstrate that the bell sound paired with morphine injections during addiction did not reduce any of the withdrawal signs other than changes in body temperature at either the 24 or 48 hr observation period $(p<.01)$. Animals not receiving bell during addiction and receiving bell during withdrawal showed no effect on any withdrawal sign measured.

In order to see if number of pairings would play a role in increasing stimulus control of withdrawal signs the number of days morphine administered was extended from 15 to 25 days (long-term - low level, Table 3). This increase in number of days permitted 20 additional pairings of the bell with morphine. As can be seen in Table 3, 50 pairings of the bell and morphine did not reverse any of the withdrawal signs other than temperature $(p<.01)$. However, the number of shakes were significantly increased and the variability of shakes between animals was reduced.

Since the increase in the number of pairings was ineffective in increasing the bell's effectiveness, the terminal dose of morphine was increased to $400 \mathrm{mg} / \mathrm{Kg} /$ day for 15 days (Table 4). Doubling of the terminal dose was also ineffective in altering the bell's ability to effect withdrawal signs other than temperature $(p<.01)$. This schedule produced fewer shakes than the $200 \mathrm{mg} / \mathrm{Kg} /$ day for a 25 -day schedule. Therefore, an attempt was made to alter withdrawal signs by using the high terminal dose (400 $\mathrm{mg} / \mathrm{Kg} /$ day) and increasing the number of days to 25 as was previously tried at 
Table 3

Effect of the Auditory Stimuls on Withdrawal Signs in Rats Made Morphine Dependent in 25 Days to $200 \mathrm{mg} / \mathrm{Kg} / \mathrm{day}$ (1ong term - low leve1)

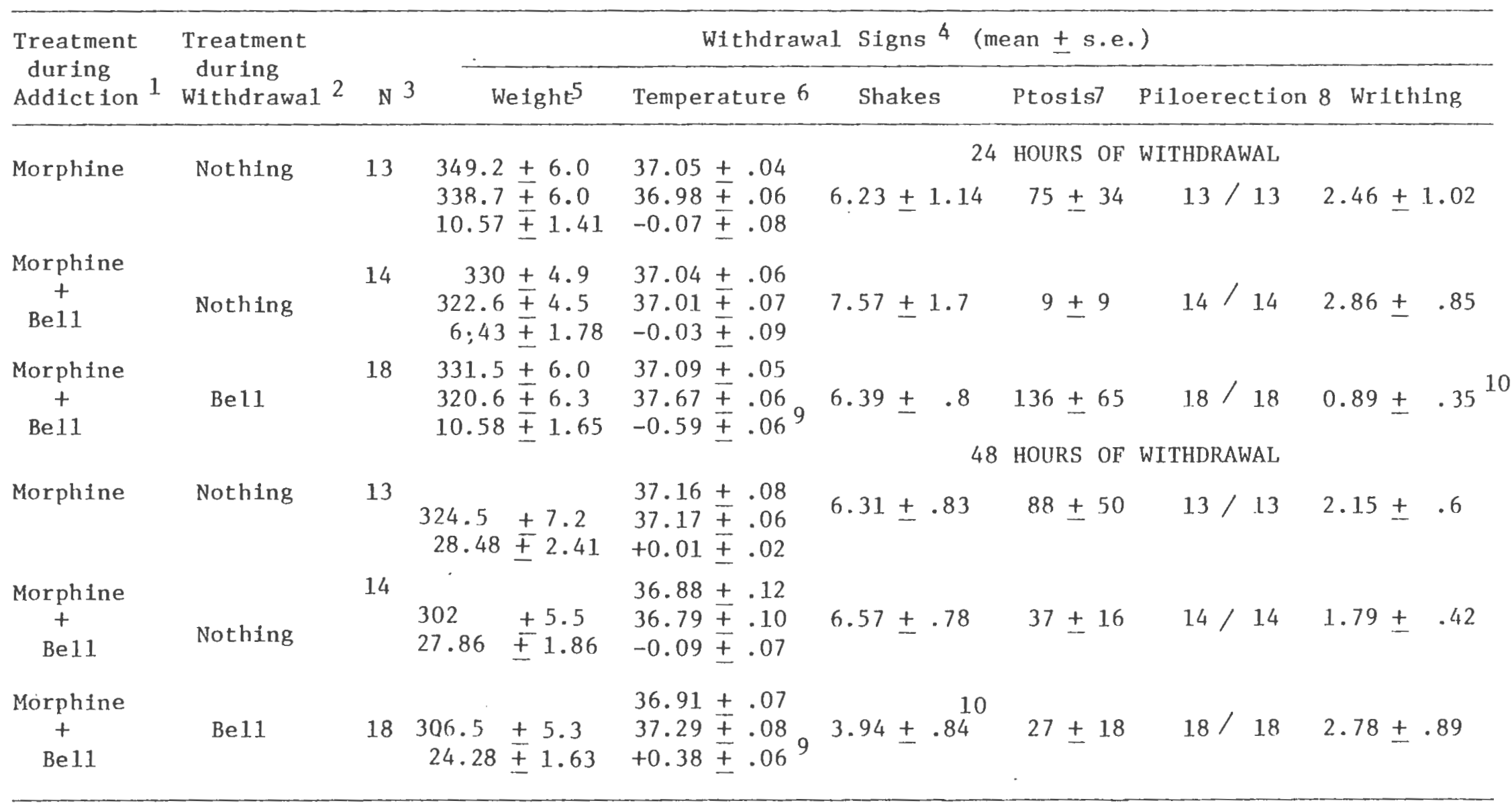

1. Refer to No. 1 of Table 2 .

2. Refer to No. 1 of Table 2 .

3. Refer to No. 3 of Table 2 .

4. Refer to No. 4 of Table 2

5. Refer to No. 5 of Table 2

6. Refer to No. 6 of Table 2 .

7. Refer to No. 7 of Table 2 .

8. Refer to No. 9 of Table 2 ,

9. Refer to No. 9 of Table 2 ( $p<.01)$

10. P value .05 using Student's t-test (each animal used as own control) 
Table

Effect of the Auditory Stimulus on Withdrawal Signs in Rats Made Morphine Dependent in 15 Days to $400 \mathrm{mg} / \mathrm{Kg} /$ day (short term-high level)

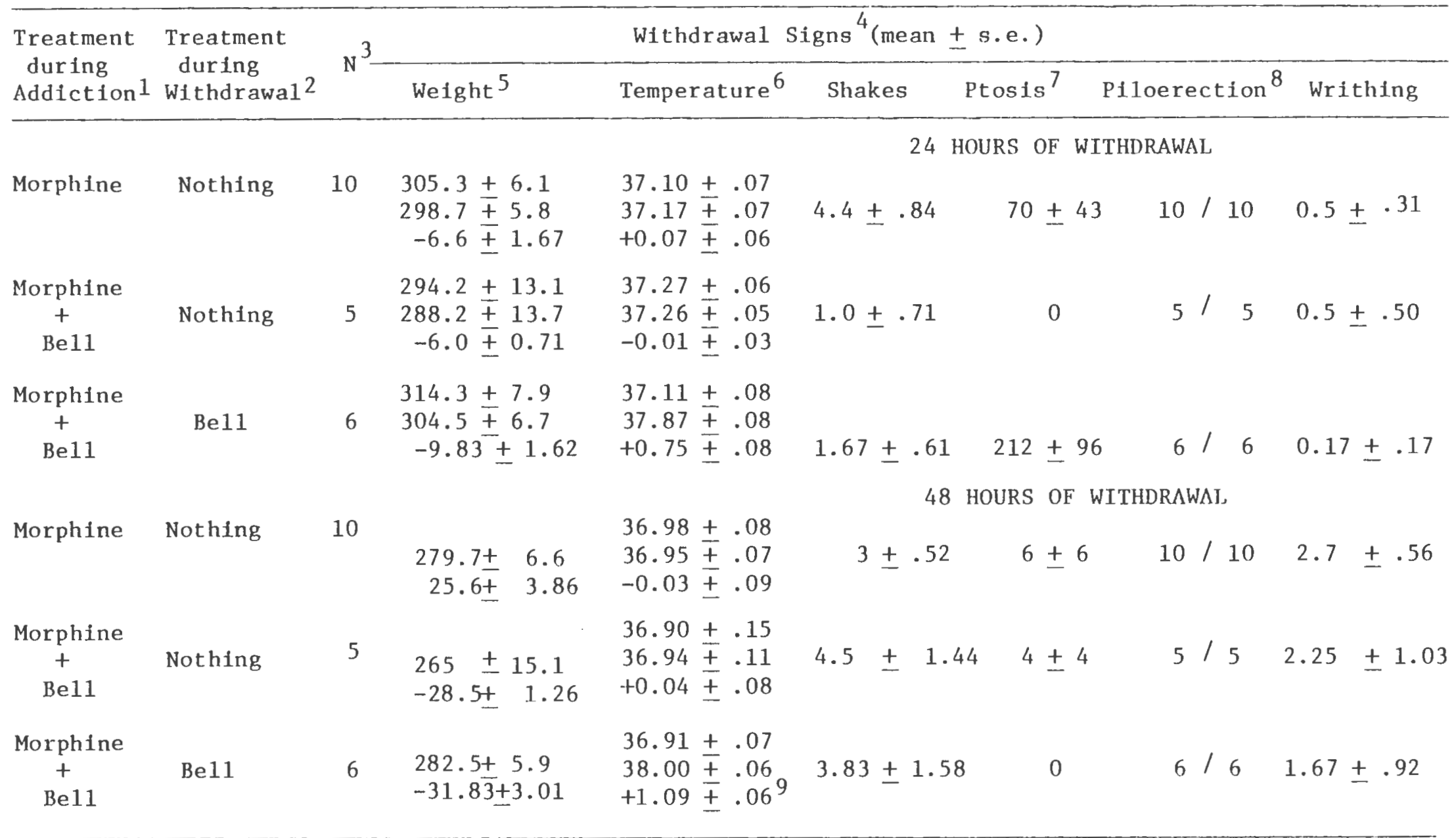

1. Refer to No. 1 of Table 2

2. Refer to No. 2 of Table 2 .

3. Refer to No. 3 of Table 2 .

4. Refer to No. 4 of Table 2 .

5. Refer to No. 5 of Table 2
6. Refer to No. 6 of Table 2 .

7. Refer to No. 7 of Table 2 .

8. Refer to No. 8 of Table 2 .

9. Refer to No. 9 of Table 2 ( $p<.01)$

10. P value .05 using Student's t-test (each animal used as own contro1 - Morphine nothing vs. Morphine + Be11 
the lower terminal dose $(200 \mathrm{mg} / \mathrm{Kg} / \mathrm{day})$. Table 5 shows that again no signs were conditionable except for body temperature $(p, .01)$. These results show that the bell was ineffective in altering withdrawal signs other than temperature even after altering the terminal dose and number of stimulus-drug pairings.

B. Alteration of Withdrawal Signs by Gustatory and Interoceptive stimuli

In order to determine the effects of a gustatory stimulus paired with morphine on withdrawal signs, a saccharin solution was infused into the rats' mouths prior to every morphine injection and then the saccharin presented to the animals at 24 and 48 hrs after the last pairing.

In the presence of saccharin, conditioned-withdrawn rats did not show an alteration in withdrawal signs measured except for temperature at $48 \mathrm{hr}$ (Table 6). A slight, but non-significant reduction of wet shakes occurred at 48 hr of withdrawal after saccharin administration.

Since auditory and gustatory stimuli were unable to significantly alter any of the withdrawal signs other than temperature it was decided to use an interoceptive stimulus (i.e., drug). In order to determine if an interoceptive stimulus is effective, alcohol was selected to be paired with each morphine injection. Control animals were given water intragastrically with each morphine injection. During withdrawal at 24 and 48 hrs all groups had their body weight, 
Table 5

Effect of the Auditory Stimulus on Withdrawal Signs in Rats, Long term (25 days) High Level of Addiction (400 mg/Kg/day)

\begin{tabular}{|c|c|c|c|c|c|c|c|c|}
\hline \multirow{2}{*}{$\begin{array}{l}\text { Treatment } \\
\text { during } \\
\text { Addiction } 1\end{array}$} & \multirow{2}{*}{$\begin{array}{l}\text { Treatment } \\
\text { during } \\
\text { Withdrawa }{ }^{2}\end{array}$} & \multirow{2}{*}{$\mathrm{N}$} & \multicolumn{6}{|c|}{ Withdrawal Signs 4 (mean \pm s.e.) } \\
\hline & & & Weight ${ }^{5}$ & Temperature ${ }^{6}$ & Shakes & Ptosis ${ }^{7}$ & Piloerection 8 & Writhing \\
\hline Morphine & None & 5 & $\begin{array}{l}288.8 \pm 4.9 \\
279.6 \pm 5.2 \\
-9.20 \pm 2.27\end{array}$ & $\begin{array}{l}37.26 \pm .12 \\
37.28 \pm .05 \\
+0.02 \pm .05\end{array}$ & $5.00 \pm 1.41$ & $\begin{array}{r}4 \text { HOURS OF } \\
52+33\end{array}$ & $\begin{array}{c}\text { WITHDRAWAL } \\
5 / 5\end{array}$ & $1.60 \pm 0.93$ \\
\hline $\begin{array}{c}\text { Morphine } \\
+ \\
\text { Be11 }\end{array}$ & None & 10 & $\begin{array}{l}299.1 \pm 8.85 \\
289.8 \pm 8.6 \\
-9.30 \pm 1.70\end{array}$ & $\begin{array}{r}37.13 \pm .05 \\
37.12 \pm .06 \\
0.00 \pm .05\end{array}$ & $5.60 \pm 0.96$ & $75+41$ & $10 / 10$ & $2.50 \pm 1.30$ \\
\hline $\begin{array}{c}\text { Morphine } \\
+ \\
\text { Bel1 }\end{array}$ & Be 11 & 10 & $\begin{array}{l}293.5 \pm 7.1 \\
283.4 \pm 6.5 \\
-10.00 \pm 1.56\end{array}$ & $\begin{array}{l}37.13+.06 \\
38.02 \pm .089 \\
-0.89 \pm .06\end{array}$ & $5.20 \pm 0.84$ & $82 \pm 35$ & $10 / 10$ & $1.70 \pm 0.75$ \\
\hline Morphine & None & 5 & $\begin{array}{c}261.4 \pm 6.5 \\
-27.40 \pm 5.07\end{array}$ & $\begin{array}{l}37.15 \pm .15 \\
37.16 \pm .08 \\
+0.01 \pm .07\end{array}$ & $\begin{array}{r}48 \\
6.20 \pm 1.07\end{array}$ & $\begin{array}{l}3 \text { HOURS OF } \\
56 \pm 35\end{array}$ & WITHDRAWAL & $2.80 \pm 1.24$ \\
\hline $\begin{array}{c}\text { Morphine } \\
+ \\
\text { Be11 }\end{array}$ & None & 10 & $\begin{array}{l}273.3 \pm 6.9 \\
-25.80 \pm 4.02\end{array}$ & $\begin{array}{l}37.02 \pm .08 \\
37.03 \pm .06 \\
+0.01 \pm .05\end{array}$ & $6.20 \pm 0.61$ & $65 \pm 30$ & $10^{/} 10$ & $3.30 \pm 0.76$ \\
\hline $\begin{array}{c}\text { Morphine } \\
+ \\
\text { Be11 }\end{array}$ & Bel1 & 10 & $\begin{array}{l}268.1 \pm 7.0 \\
-25.40 \pm 4.28\end{array}$ & $\begin{array}{l}36.95 \pm .09 \\
37.85 \pm .08 \\
-0.90 \pm .07\end{array}$ & $5.3 \pm 0.79$ & $72 \pm 44$ & $10 / 10$ & $1.50 \pm 0.50$ \\
\hline
\end{tabular}

1. Refer to No. 1 of Table 2

2. Refer to No. 2 of Table 2

3. Refer to No. 3 of Table 2

4. Refer to No. 4 of Table 2

5. Refer to No. 5 of Table 2
5. Refer to No. 5 of Table 2 .

6. Refer to No. 6 of Table 2.

7. Refer to No. 7 of Table 2.

8. Refer to No. 8 of Table 2 .

9. Refer to No. 9 of Table 2 ( $p$.01) 
Table 6

Effect of Gustatory Stimulus (Saccharine) on Withdrawal Signs in Rats During the Primary Abstinence Period

\begin{tabular}{|c|c|c|c|c|c|c|c|c|c|}
\hline \multirow{2}{*}{$\begin{array}{l}\text { Treatment } \\
\quad \text { during } \\
\text { Addiction }\end{array}$} & \multirow{2}{*}{$\begin{array}{l}\text { Treatment } \\
\text { during } \\
\text { Withdrawa }{ }^{2}\end{array}$} & \multirow{2}{*}{$N^{3}$} & \multicolumn{7}{|c|}{ Post Withdrawal $\operatorname{Sign}^{4}$ (mean \pm s.e.) } \\
\hline & & & Weight ${ }^{5}$ & Temperature $^{6}$ & Shakes & $\operatorname{tosis}^{7}$ & Pi] & oerection $^{8}$ & Writhing \\
\hline & & & & & & 4 HOURS & OF & WITHDRAWAL & \\
\hline $\begin{array}{c}\text { Morphine } \\
+ \\
\mathrm{H}_{2} \mathrm{O}\end{array}$ & $\mathrm{H}_{2} \mathrm{O}$ & 18 & $\begin{array}{l}340.9 \pm 5.7 \\
334.1 \pm 5.8 \\
-6.78 \pm 1.38\end{array}$ & $\begin{array}{l}36.93 \pm .08 \\
36.87 \pm .08 \\
-0.07 \pm .05\end{array}$ & $7.44 \pm 1.86$ & $46 \pm$ & 23 & $2.1 \pm .15$ & $1.61 \pm .42$ \\
\hline $\begin{array}{c}\text { Morphine } \\
+ \\
\text { SAC }\end{array}$ & SAC & 18 & $\begin{array}{l}353.7 \pm 6.0 \\
345.8 \pm 6.6 \\
-7.89 \pm 1.83\end{array}$ & $\begin{array}{l}36.99 \pm .07 \\
37.19 \pm .09 \\
+0.20 \pm .05\end{array}$ & $6.89 \pm 1.55$ & $41 \pm$ & 21 & $1.9 \pm .20$ & $1.78 \pm .46$ \\
\hline $\begin{array}{c}\text { Morphine } \\
+ \\
\mathrm{H}_{2} \mathrm{O}\end{array}$ & $\mathrm{H}_{2} \mathrm{O}$ & 18 & $\begin{array}{l}310.6 \pm 6.2 \\
30.44 \pm 2.54\end{array}$ & $\begin{array}{c}36.72 \pm .08 \\
36.61 \pm .05 \\
-0.11 \pm .05\end{array}$ & $8.11 \pm 1.67$ & $\begin{array}{l}3 \text { HOURS } \\
38 \pm\end{array}$ & $\begin{array}{r}\text { OF } \\
-23\end{array}$ & $\begin{array}{l}\text { WITHDRAWAI } \\
\qquad 2.3 \pm .10\end{array}$ & $2.5 \pm .72$ \\
\hline
\end{tabular}

1. Refer to No. 1. of Table 2 .

2. Refer to No. 2 of Table 2 .

3. Refer to No. 3 of Table 2.

4. Refer to No. 4 of Table 2.

5. Refer to No. 5 of Table 2 .

6. Refer to No. 6 of Table 2.

7. Refer to No. 7 of Table 2 .
8. P value $\prec .05$ using student's t-test (each animal used as own control).

9. P value $<.05$ using student's t-test (comparing morphine $+\stackrel{b}{\circ}$ $\mathrm{sac}-\mathrm{Sac}$ vs. Morphine $+\mathrm{H}_{2} \mathrm{O}-\mathrm{H}_{2} \mathrm{O}$ ). 
temperature, shakes, ptosis, piloerection and writhing measured.

In the presence of alcohol at 24 hrs withdrawal, conditioned rats exhibited an increase in temperature and a non-significant reduction in shakes (Table 7) compared to the control groups. However, presentation of alcohol to the experimental group at 48 hrs of withdrawal had no effect on temperature or shakes in addition to no effect on any of the other measured symptoms.

Since the use of alcohol as an intereoceptive stimulus was unable to reliably reduce signs other than temperature, it was necessary to try another drug stimulus to check if an intereoceptive stimulus could become a conditional stimulus. Data presented in Table 8 show that the second drug chosen, apomorphine $(1.25 \mathrm{mg} / \mathrm{Kg})$, was also ineffective in significantly altering any of the withdrawal signs at either 24 or 48 hrs after the last apomorphine-morphine pairing.

one additional drug, pentobarbital, was used as an intereoceptive stimulus. As the case with the other drugs, pentobarbital was ineffective in altering any withdrawal sign significantly except temperature at either 24 or $48 \mathrm{hrs}$ of withdrawal (Table 9). Pentobarbital affected the temperature of both paired and unpaired animals; however, instead of increasing temperature as the auditory and gustatory stimuli did, pentobarbital caused a significant decrease in body temperature. This drop in temperature of drug alone 
Tab1e 7

Effect of Alcohol (Intereoceptive) Stimulus on Withdrawal Sign in Rats During the Primary Abstinence Period

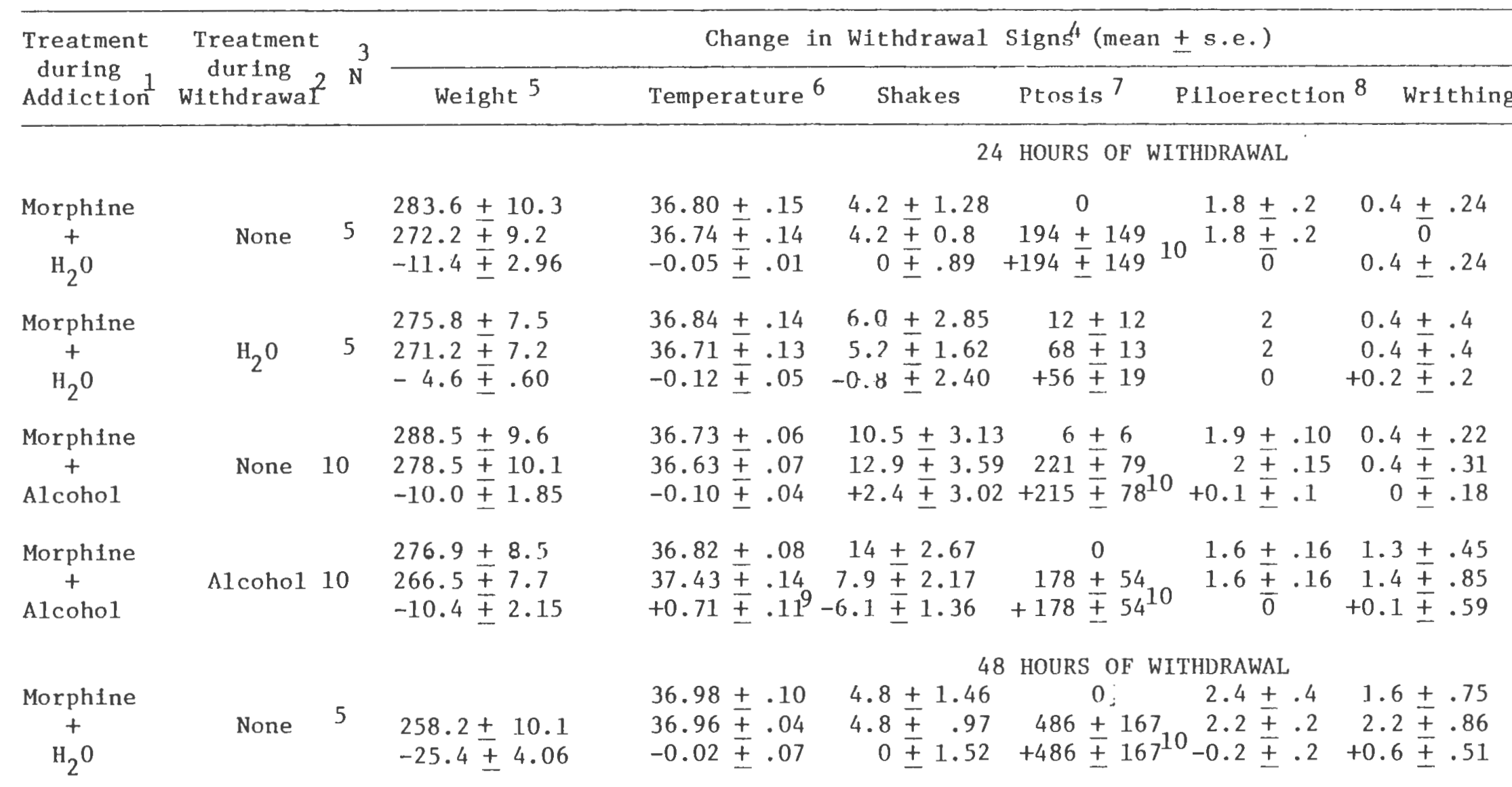


Table 7 (continued)

\begin{tabular}{|c|c|c|c|c|c|c|c|c|c|c|}
\hline \multirow{2}{*}{$\begin{array}{l}\text { Treatment } \\
\text { during } \\
\text { Addiction }\end{array}$} & \multirow{2}{*}{$\begin{array}{c}\text { Treatment } \\
\text { during } \\
\text { withdrawal }\end{array}$} & \multirow{2}{*}{$2^{N^{3}}$} & \multicolumn{8}{|c|}{ Change in Withdrawal Signs ${ }^{4}$ (mean \pm s.e.) } \\
\hline & & & Weight 5 & Temperature $^{6}$ & Shakes & Ptosi & is $^{7}$ & Piloerection 8 & & Writhing \\
\hline $\begin{array}{c}\text { Morphine } \\
+ \\
\mathrm{H}_{2} \mathrm{O}\end{array}$ & $\mathrm{H}_{2} \mathrm{O}$ & 5 & $\begin{array}{l}245.6 \pm 3.8 \\
-30.2 \pm 5.43\end{array}$ & $\begin{array}{l}36.89 \pm .07 \\
36.88 \pm .10 \\
-0.01 \pm .09\end{array}$ & $\begin{array}{l}7.2 \pm 2.8 \\
6.4 \pm 1.03 \\
-0.8 \pm 1.98\end{array}$ & $\begin{array}{r}232 \\
+232\end{array}$ & $\begin{array}{l}0 \\
\pm 102 \\
\pm 102\end{array}$ & $\begin{array}{l}2.2 \pm .2 \\
2.2 \pm .2\end{array}$ & $\begin{array}{r}1.8 \\
2.0 \\
+0.2\end{array}$ & $\begin{array}{l} \pm 1.11 \\
\pm \quad .95 \\
\pm 1.07\end{array}$ \\
\hline $\begin{array}{l}\text { Morphine } \\
+ \\
\text { Alcoho1 }\end{array}$ & Alcohol & 10 & $\begin{array}{r}246.8+7.24 \\
29.7 \pm 1.56\end{array}$ & $\begin{array}{r}36.64 \pm .23 \\
36.75 \pm .25 \\
+0.11 \pm .09\end{array}$ & $\begin{array}{r}11.6 \pm 2.48 \\
9.0 \pm 1.83 \\
-2.6 \pm 1.33\end{array}$ & $\begin{array}{r}298 \\
+298\end{array}$ & 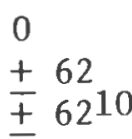 & $\begin{array}{r}2.4 \pm .16 \\
2.5 \pm .17 \\
0_{+0.1 \pm .18}\end{array}$ & $\begin{array}{r}3.2 \\
2.9 \\
-0.3\end{array}$ & $\begin{array}{ll} \pm & .88 \\
\pm & .25 \\
\pm & .91\end{array}$ \\
\hline
\end{tabular}

1. Refer to No, 1 of Table 2 .

2. Refer to No. 2 of Table 2 .

3. Refer to No. 3 of Table 2 .

4. Signs measured prior to treatment during withdrawal and $30 \mathrm{~min}$ following treatment. Difference was determined by using each animal as own control.

5. Refer to No. 5 of Table 2 .

6. Refer to No. 6 of Table 2 .

7. Measured in seconds (duration) prior to and $30 \mathrm{~min}$. Following treatment during withdrawal.

8. A11 animals showed piloerection, these numbers represent a rating score prior to and 30 min following treatment during withdrawa1.

9. Refer to No. 9 of Table 2 (p $<05)$

10. Refer to No. 10 of Table 3 (p $<.05)$ 
Table 8

Effect of Apomorphine (Intereoceptive) Stimulus on Withdrawal Signs in Rats, During the Primary Abstinence Period

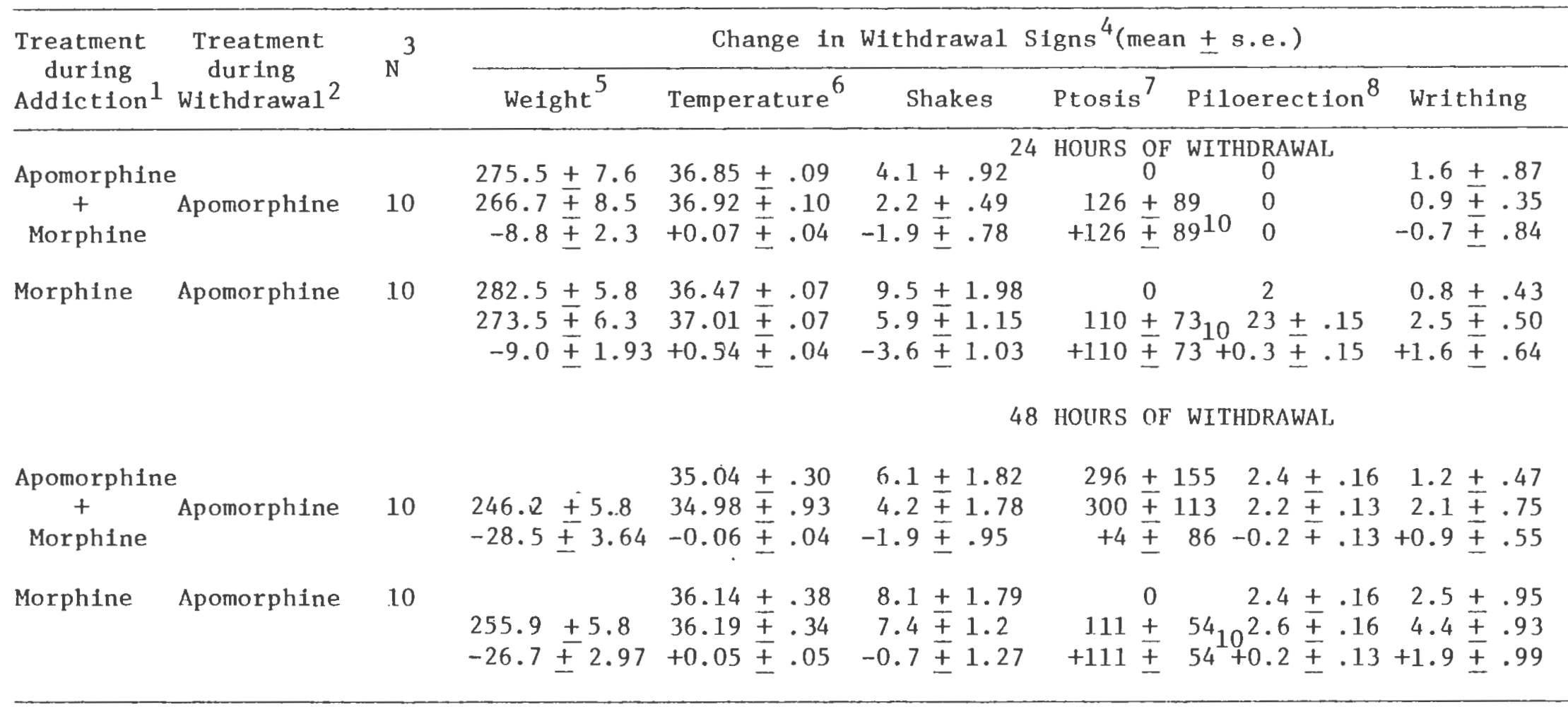

1. Refer to No. 1 of Table 2 .

2. Refer to No. 2 of Table 2 .

3. Refer to No. 3 of Table 2.

4. Refer to No. 4 of Table 7.

5. Refer to No. 5 of Table 2 .

6. Refer to No. 6 of Table 2 .
7. Refer to No. 7 of Table 7 .

8. Refer to No. 8 of Table 7

9. Refer to No. 9 of Table 2 (p :.01).

10. Refer to No. 10 of Table 3 ( $p \vee .05$ ) 
TABLE 9

Effect of Pentobarbital (Intereoceptive) Stimulus on Withdrawal Signs in Rats, During the Primary Abstinence Period

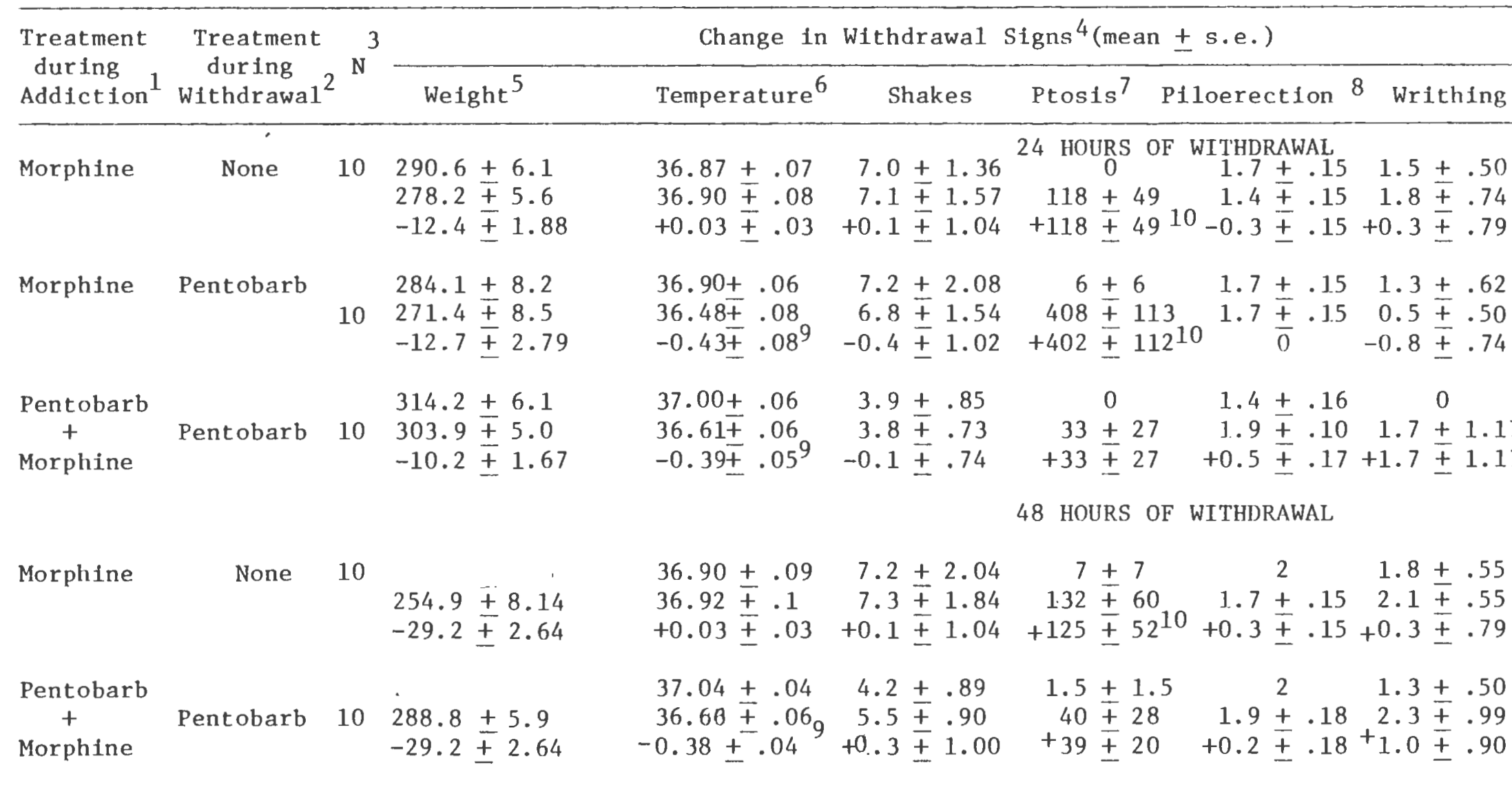

1. Refer to No. 1 of Table 2 .

2. Refer to No. 2 of Table 2 .

3. Refer to No. 3 of Table 2.

4. Refer to No. 4 of Table 7.

5. Refer to No. 5 of Table 2 .
6. Refer to No. 6 of Table 2 .

7. Refer to No. 7 of Table 7 .

8. Refer to No. 8 of Table 7.

9. Refer to No. 9 of Table $2(p ; .01)$.

10. Refer to No. 10 of Table $3(p: .05)$. 
Table 10

Effect of the Conditional Stimulus (0il of Anise) Duration on Withdrawal Sign During the Primary Abstinence Period

\begin{tabular}{|c|c|c|c|c|c|c|c|}
\hline \multirow{2}{*}{$\begin{array}{l}\text { Treatment } \\
\text { during } \\
\text { Addiction }\end{array}$} & \multirow{2}{*}{$\begin{array}{l}\text { Treatment During } \\
\text { Withdrawa } 11 \\
\text { (minutes) }\end{array}$} & \multirow[b]{2}{*}{$\mathrm{N}^{2}$} & \multicolumn{5}{|c|}{ Change in Withdrawal Signs ${ }^{3}$ (mean + s.e.) } \\
\hline & & & Temperature 4 & Shakes & Ptosis 5 & Piloerection 6 & Writhing \\
\hline CS-morphine & NO $(\mathrm{Cs})$ & 10 & $\begin{array}{l}37.16 \pm .07 \\
37.70 \pm .06 \\
-0.06 \pm .03\end{array}$ & $\begin{array}{l}11.7 \pm 2.7 \\
14.2 \pm 3.22 \\
+2.5 \pm 1.32\end{array}$ & $\begin{array}{r}54 \pm 36 \\
264 \pm 82 \\
+210 \pm 61\end{array}$ & $\begin{array}{r}\text { HOURS OF WITHDRAWAL } \\
1.7 \pm .15 \\
1.7 \pm .15 \\
0 \pm .15\end{array}$ & $\begin{array}{r}1.4 \pm .81 \\
2.1 \pm 1.04 \\
+0.7 \pm .52\end{array}$ \\
\hline CS-morphine & $\operatorname{cs}(2)$ & 10 & $\begin{array}{l}36.98 \pm .07 \\
37.16 \pm .08 \\
+0.18 \pm .08\end{array}$ & $\begin{array}{l}8.2 \pm 2.78 \\
7.4 \pm 2.96 \\
-0.8 \pm .93\end{array}$ & $\begin{array}{r}76 \pm 59 \\
316 \pm 116 \\
+240 \pm 87\end{array}$ & $\begin{array}{l}1.7 \pm .15 \\
1.7 \pm .15 \\
0 \pm .21\end{array}$ & $\begin{array}{r}.9 \pm .6 \\
.6 \pm .22 \\
-0.3 \pm .56\end{array}$ \\
\hline CS-morphine & $\operatorname{cs}(30)$ & 10 & $\begin{array}{l}37.17 \pm .08 \\
37.61 \pm .13 \\
+0.44 \pm .147\end{array}$ & $\begin{array}{r}12.9 \pm 3.73 \\
7.8 \pm 1.87 \\
-5.1 \pm 3.03\end{array}$ & $\begin{array}{r}21 \pm 21 \\
668 \pm 119 \\
+647 \pm 1147\end{array}$ & $\begin{array}{r}1.5 \pm .17 \\
1.3 \pm .15 \\
-0.2 \pm .13\end{array}$ & $\begin{array}{r}1.4 \pm .54 \\
.5 \pm .31 \\
-0.9 \pm .60\end{array}$ \\
\hline CS-morphine & $\operatorname{cs}(60)$ & 10 & $\begin{array}{l}36.98 \pm .07 \\
37.48 \pm .09 \\
+0.49 \pm .11^{7}\end{array}$ & $\begin{array}{r}10.5 \pm 2.01 \\
7.1 \pm 06 \\
-3.4 \pm 2.01\end{array}$ & $\begin{array}{c}0 \\
556 \pm 113 \\
+556 \pm 113^{7}\end{array}$ & $\begin{array}{r}1.4 \pm .16 \\
1.4 \pm .16 \\
0 \pm .15\end{array}$ & $\begin{array}{r}.5 \pm .22 \\
.6 \pm .34 \\
+0.1 \pm .43\end{array}$ \\
\hline CS-morphine & NO $(\mathrm{CS})$ & 10 & $\begin{array}{l}36.93 \pm .07 \\
36.97 \pm .05 \\
+0.04 \pm .04\end{array}$ & $\begin{array}{r}9.3 \pm 1.58 \\
10.3 \pm 2.23 \\
+1.0 \pm 1.03\end{array}$ & $\begin{array}{r}77 \pm 38 \\
164 \pm 48 \\
+87 \pm 59\end{array}$ & $\begin{array}{l}\text { HOURS OF WITHDRAWAL } \\
2.1 \pm .18 \\
2.2 \pm .2 \\
+0.1 \pm .1\end{array}$ & $\begin{array}{r}1.7 \pm .6 \\
2.3 \pm .62 \\
+0.6 \pm .97\end{array}$ \\
\hline CS-morphine & $\operatorname{CS}(30)$ & 10 & $\begin{array}{l}37.12 \pm .06 \\
+0.37 \pm .057\end{array}$ & $\begin{array}{r}11.5 \pm 1.10 \\
6.3 \pm .678 \\
-4.75 \pm 1.04\end{array}$ & $\begin{array}{c}0 \\
397 \pm 767 \\
+397 \pm 76\end{array}$ & $\begin{array}{c}1.95 \pm .05 \\
1.85 \pm .08 \\
-0.1 \pm .07\end{array}$ & $\begin{array}{r}1.6 \pm .46 \\
.8 \pm .29 \\
-0.8 \pm .51\end{array}$ \\
\hline
\end{tabular}

1. Refer to No. 2 of Table 2.

2. Refer to No. 3 of Table 2.

3. Refer to No. 4 of Table 2.

4. Refer to No. 6 of Table 2 .

5. Refer to No. 7 of Table 7 .
6. Refer to No. 8 of Table 7.

7. Refer to No. 9 of Table $2(\mathrm{p} \& .01)$.

8. Refer to No. 10 of Table $3(p \therefore 05)$. 
may mask the pentobarb's conditional effect. However, since a control group which received pentobarb during withdrawal also showed a drop in temperature of the same amount, this idea seems unlikely (Table 9)

C. Olfactory Stimulus Effect on Withdrawal Signs: Physical, Behavioral and Biochemical

The effect of an olfactory stimulus odor is shown in Table 10 as a more effective stimulus in being able to alter not only temperature $(p<0.01)$ as the bell and saccharin did, but also shakes $(p<0.05)$, and ptosis $(p<0.01)$. As can be seen in Table 10, it was necessary to present the conditional stimulus (CS) for a period of time exceeding $2 \mathrm{~min}$, but not more than $30 \mathrm{~min}$. Also, the effectiveness of anise oil as a CS was evident at both the 24 and $48 \mathrm{hr}$ withdrawal measurements.

In order to substantiate the effectiveness of anise odor as a CS, a number of control groups were done (Table 11). As shown in Table 11 the control groups included: 1) CS presented to naive animals - CS presented during withdrawal; 2) CS-morphine pairing during addiction - no treatment during withdrawal; 3) morphine alone during addiction - CS presented during withdrawal; 4) random CS + morphine during addiction CS presented during withdrawal and 5) morphine alone during addiction - no treatment during withdrawal. The anise odor did not affect any withdrawal signs of the control groups thus supporting the fact that the cs must be presented during withdrawal to CS-morphine paired animals, if it is to be 
Table 11

Effect of Conditional STimulus (011 of Anise) on Rats Made Morphine-Dependent for 25 Days to $200 \mathrm{mg} / \mathrm{Kg} / \mathrm{day}$

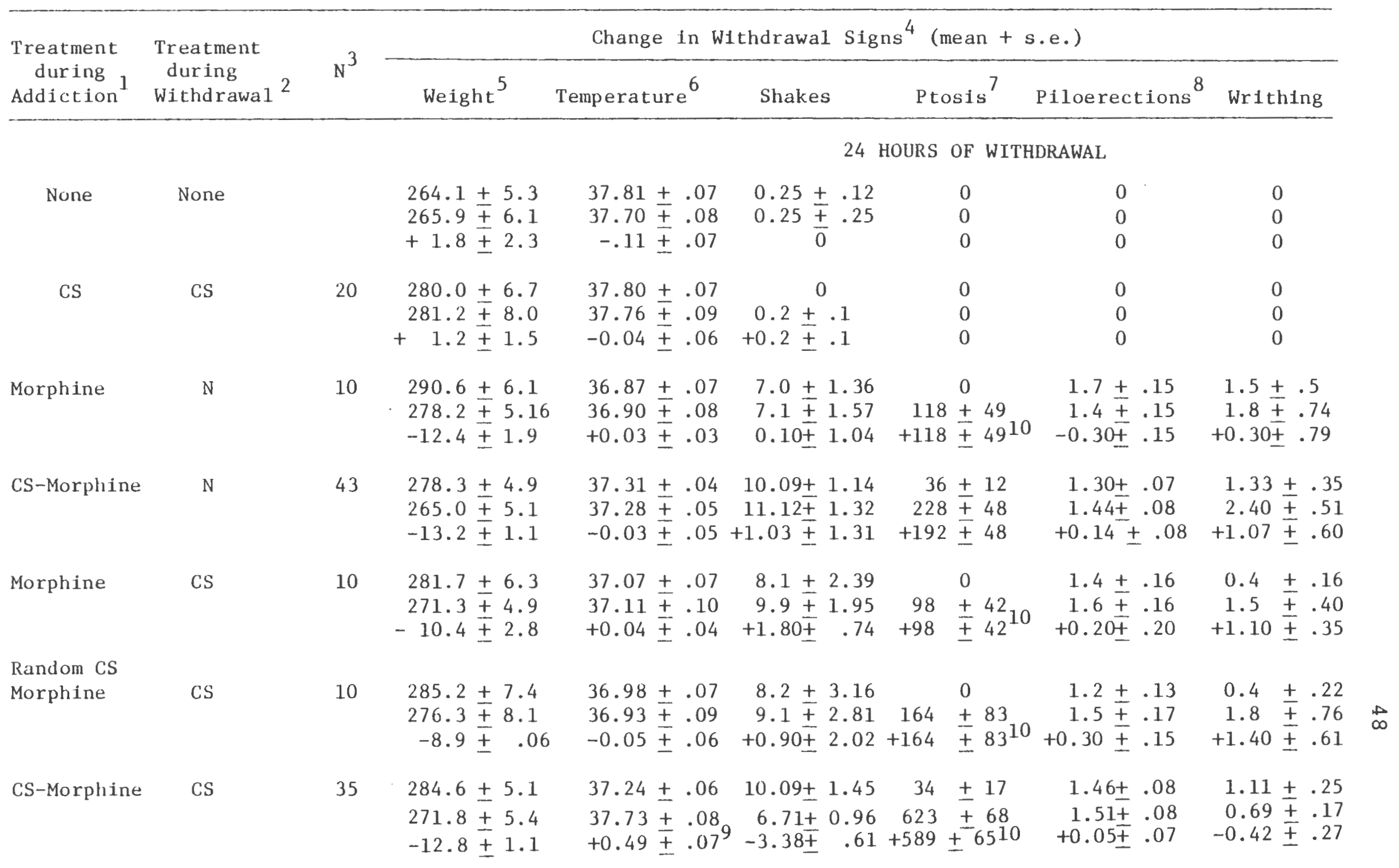


Table $11-($ Continued)

Effect of Conditional Stimulus (Oil of Anise) on Rats Made Morphine Dependent for 25 days to $200 \mathrm{mg} / \mathrm{Kg} / \mathrm{day}$

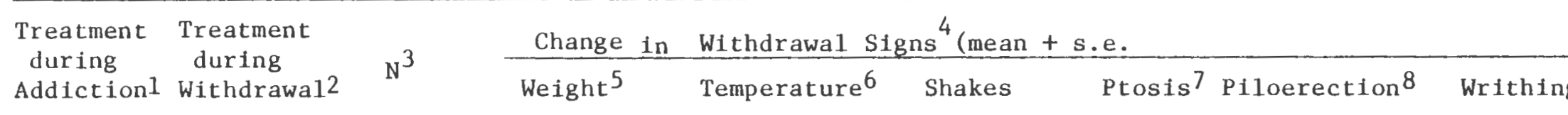

48 HOURS OF WTTHDRAWAL

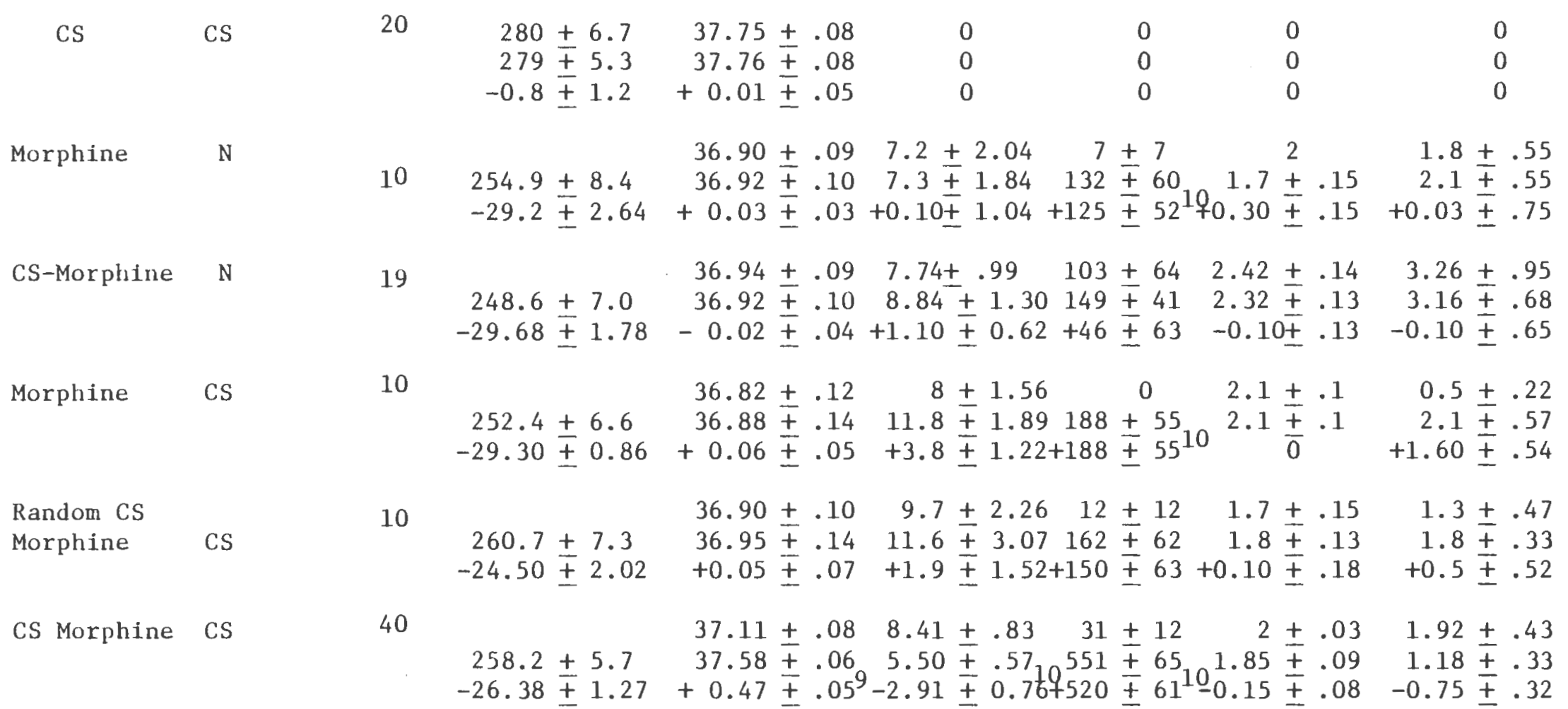

1. Refer to No. 1 of Table 2 .

2. Refer to No. 2 of Table 2.

3. Refer to No. 3 of Table 2.

4. Refer to No. 4 of Table 7.
5. Refer to No. 5 of Table 2 .

6. Refer to No. 6 of Table 2 .

7. Refer to No. 7 of Table 7.

8. Refer to No. 8 of Table 7.
9. Refer to No. 9 of Table 2

$$
\text { ( } \mathrm{p}<.01 \text { ) }
$$

10. Refer to No. 10 of Table 3 $(\mathrm{p}<.05)$ 
effective in reducing specific withdrawal signs. The effect on ptosis by the CS showed an increase rather than a decrease upon observation; this effect was significant ( $p<.05$ ) (Table 11).

As can be seen in Table 12 the CS was able to significantly reduce spontaneous aggression in animals which had a history of CS-morphine pairing (Chi-square analysis, p <.05). Anise odor, thus far, has been effective in altering physical (temperature) and behavioral withdrawal signs (aggression, ptosis, shakes and writhing). However, if anise oil were able to alter biochemical parameters of withdrawal, this would give conclusive support of its true effectiveness as a conditional stimulus.

Blood glucose and homovanillic acid measures were chosen as the biochemical parameter to be monitored in the conditioned and unconditioned animals. Data presented in Table 13 show the effect of the CS on blood glucose levels of conditioned and unconditioned rats. The CS was able to increase the glucose level in conditioned animals at 24 ( $p: .01$ ) and $48 \mathrm{hr}(\mathrm{p}<.05)$ of withdrawal. But as can be seen in Table 13, the CS groups showed no significant increase in blood glucose when compared to saline-treated animals.

Data summarized in Table 14 shows that HVA was also increased following anise oil presentation to anise oilmorphine animals during withdrawal at 24 and 72 hr (p (.05). The increase in HVA was similar to that seen following morphine 
Table 12

Effect of Conditional Stimulus (Oil of Anise) on Withdrawal

Induced Aggression

\begin{tabular}{cccc}
\hline $\begin{array}{c}\text { Treatment } \\
\text { during } \\
\text { Addiction }\end{array}$ & $\begin{array}{c}\text { Treatment } \\
\text { during } \\
\text { Withdrawa1 }\end{array}$ & $\mathrm{N}^{3}$ & $\begin{array}{c}\% \\
\text { Groups } \\
\text { Fighting }\end{array}$ \\
\hline CS & CS & 4 & 0 \\
Morphine & None & 5 & 80 \\
CS-Morphine & None & 8 & 88 \\
Morphine & CS & 5 & 100 \\
Random CS-Morphine & CS & 5 & 80 \\
CS-Morphine & CS & 12 & $42^{4}$ \\
\hline
\end{tabular}

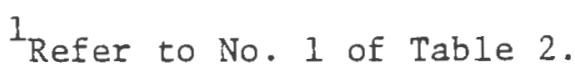

2 Refer to No. 2 of Table 2.

3 Number of groups ( 5 animals/group)

${ }^{4}$ Chi square analysis $\because \quad 24.78 ; p<.05$. 
Table 13

Effect of the Conditional Stimulus (Oil of Anise) on Blood Glucose Levels in Naive and Morphine Withdrawn Rats

\begin{tabular}{|c|c|c|c|}
\hline Group 1 & Treatment ${ }^{2}$ & $N^{3}$ & $\begin{array}{l}\text { Blood glucose levels } 4 \\
\text { (mg } \% \pm \text { s.e.) }\end{array}$ \\
\hline \multirow[t]{2}{*}{ Naive Rats } & Saline & 14 & $99 \pm 3.8$ \\
\hline & Morphine $20 \mathrm{mg} / \mathrm{Kg}$ & 7 & $140.2 \pm 4.9^{5}$ \\
\hline \multirow[t]{3}{*}{$\begin{array}{l}24 \mathrm{Hr} \\
\text { Withdrawal }\end{array}$} & Saline & 5 & $96 \pm 4.2$ \\
\hline & No CS & 20 & $101.4 \pm 3.0$ \\
\hline & $\mathrm{CS}$ & 10 & $118.4 \pm 3.1^{5}$ \\
\hline \multirow[t]{5}{*}{$\begin{array}{l}48 \mathrm{Hr} \\
\text { Withdrawal }\end{array}$} & Saline & 5 & $96.1 \pm 2.5$ \\
\hline & $\begin{array}{c}\text { Random CS } \\
+ \\
\mathrm{CS}\end{array}$ & 5 & $99.4 \pm 4.4$ \\
\hline & No $C S+C S$ & 5 & $98.6 \pm 4.9$ \\
\hline & No CS & 5 & $104.3 \pm 3.0$ \\
\hline & $\mathrm{CS}$ & 5 & $115.7 \pm 7.3^{6}$ \\
\hline
\end{tabular}

I Terminal dose of morphine for withdrawn animals was $200 \mathrm{mg} / \mathrm{kg} / \mathrm{day}$. 2 Refer to No. 2 of Table 2.

3 Refer to No. 3 of Table 3 .

4 Blood drawn 30 min following treatment.

${ }_{6}^{5}$ Refer to No. 9 of Table 2 ( $\left.p<.01\right)$.

6 Refer to No. 10 of Table $3(\mathrm{p}: 05)$ 
Table 14

Effect of the Conditional Stimulus ( $0 i 1$ of Anise) on Striatal Homovanillic Acid Levels in Naive and Morphine Withdrawn Rats

\begin{tabular}{|c|c|c|c|}
\hline Group 1 & Treatment ${ }^{2}$ & $N^{3}$ & $\begin{array}{l}\text { HVA LEVELS } 4 \\
\text { (ug HVA/g Striatum } \pm \text { s.e.) }\end{array}$ \\
\hline \multirow[t]{3}{*}{ Naive Rats } & Saline & 5 & $0.446 \pm .032$ \\
\hline & Morphine $10 \mathrm{mg} / \mathrm{Kg}$ & 5 & $0.728 \pm .049^{5}$ \\
\hline & Morphine $100 \mathrm{mg} / \mathrm{Kg}$ & 5 & $0.855 \pm .082^{5}$ \\
\hline \multirow[t]{2}{*}{$\begin{array}{l}24 \mathrm{Hr} \\
\text { Withdrawal }\end{array}$} & No CS & 5 & $0.450 \pm .014$ \\
\hline & CS & 5 & $0.591 \pm .026^{6}$ \\
\hline \multirow[t]{4}{*}{$\begin{array}{l}72 \mathrm{Hr} \\
\text { Withdrawal }\end{array}$} & Morphine $10 \mathrm{mg} / \mathrm{Kg}$ & 5 & $0.507 \pm .017$ \\
\hline & Morphine $100 \mathrm{mg} / \mathrm{Kg}$ & 5 & $0.838 \pm .084^{5}$ \\
\hline & No CS & 5 & $0.480 \pm .042$ \\
\hline & CS & 5 & $0.613 \pm .0516$ \\
\hline
\end{tabular}

$1_{\text {Refer to No. } 1 \text { of Table } 13 .}$

2 Refer to No. 2 of Table 2.

3 Pairs of animals.

4 Animals were sacrificed 30 min following treatment.

5 Refer to No. 9 of Table 2 ( $p<.01$ ).

6 Refer to No. 10 of Table $3(p<.05)$. 
(10 $\mathrm{mg} / \mathrm{kg}$ ) given to $72 \mathrm{hr}$ withdrawn animals but not as great as a 10-fold high morphine (100 $\mathrm{mg} / \mathrm{Kg})$ dose given at $72 \mathrm{hrs}$ (Table 14).

D. Reversal of the Action of Olfactory stimulus as a CS by Naloxone

Data presented in Table 15 show the effects of four different doses of naloxone given to conditioned animals presented the CS during withdrawal. As can be seen, different doses of naloxone were found to reverse the cs's effect on specific withdrawal signs. Naloxone given at a dose of $0.04 \mathrm{mg} / \mathrm{Kg}$ was ineffective in blocking any of the signs measured. However, $0.16 \mathrm{mg} / \mathrm{kg}$ of naloxone was able to block the CS reduction of writhing. At $0.64 \mathrm{mg} / \mathrm{Kg}$ of naloxone the temperature increase seen following the CS was not only blocked, but a further reduction due to the narcotic antagonist was observed. Also, the effect on shake behavior was completely blocked at a dose of $0.64 \mathrm{mg} / \mathrm{Kg}$ (naloxone). Ptosis was increased which exceeded CS's effect, but naloxone by itself in morphine dependent animals causes an increase in ptosis by itself, thus making it difficult to obtain any meaning with relation to the CS at either 0.64 or $2.5 \mathrm{mg} / \mathrm{Kg}$. These data along with data previously reported by this lab (Drawbaugh \& Lal, 1974) using a bell sound (CS) suggest the hypothesis that the CS and morphine may indeed work on the same receptors. Present evidence that an endogenous morphinelike substance exists may be the means of the cs effect (this will be discussed in detail later). 
Table 15

Effect of Naloxone Pretreatment on Conditioned Animals Presented the Conditional Stimulus During Withdrawal

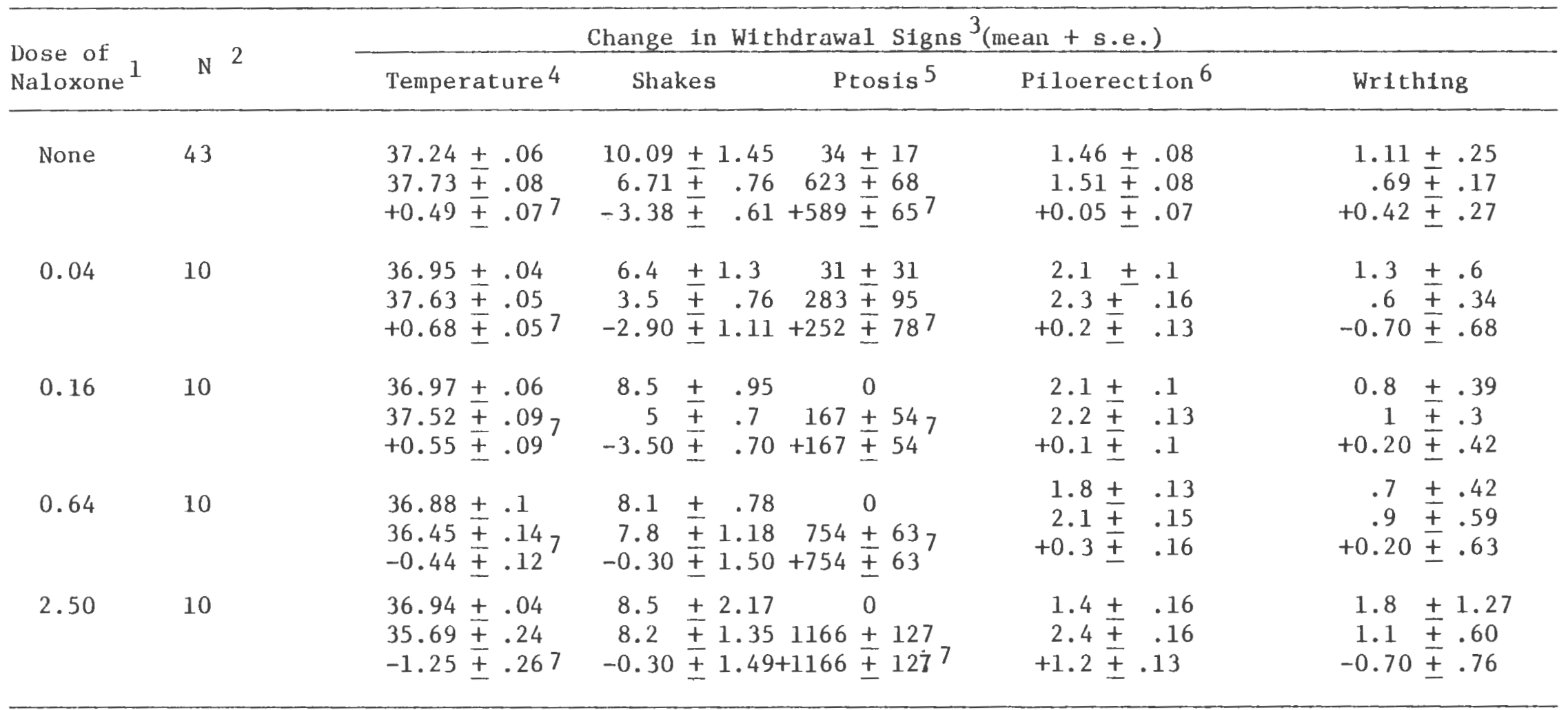

$1_{\mathrm{mg} / \mathrm{Kg}}$ given i.p.

2 Refer to No. 3 of Table 2.

3 Refer to No. 4 of Table 7.

4 Refer to No. 6 of Table 2 .

5 Refer to No. 7 of Table 7 .
${ }^{6}$ Refer to No. 8 of Table 7.

7 Refer to No. 9 of Table 2 ( $p<.01)$

${ }^{8}$ Refer to No. 10 of Table $3(\mathrm{p}<.05)$ 
Data presented in Table 16 show that Naloxone's $(2.5$ $\mathrm{mg} / \mathrm{Kg}$ ) effect on blood glucose levels was very unpredictable. A slight, insignificant, decrease in blood glucose levels was observed at $24 \mathrm{hr}$ and an increase at $48 \mathrm{hr}$. Thus, even though it seemed to block the cs effect as shown in this table it is very difficult to interpret because of naloxone's effects in animals not treated with the CS during withdrawal. 
Table 16

Effect of Naloxone Pretreatment on Blood Glucose Levels in Conditioned Animals Presented the Conditional Stimulus During Withdrawal

\begin{tabular}{|c|c|c|c|}
\hline Group ${ }^{1}$ & Treatment ${ }^{2}$ & $\mathrm{~N}^{3}$ & $\begin{array}{l}\text { Blood glucose levels } \\
\text { (mg } \pm \text { S.E.) } 4\end{array}$ \\
\hline Naive rats & $\begin{array}{l}\text { Saline } \\
\text { Morphine } \\
\text { Naloxone }\end{array}$ & $\begin{array}{r}14 \\
7 \\
10\end{array}$ & $\begin{array}{r}99 \pm 3.8 \\
140.2 \pm 4.9 \\
90.3 \pm 4.1\end{array}$ \\
\hline $\begin{array}{l}24 \mathrm{Hr} \\
\text { Withdrawal }\end{array}$ & $\begin{array}{l}\text { Saline } \\
\text { CS } \\
\text { Naloxone } 6 \\
\text { CS + Naloxone } 6\end{array}$ & $\begin{array}{l}5 \\
10 \\
10 \\
10\end{array}$ & $\begin{array}{r}96 \pm 4.2 \\
118.4 \pm 3.1 \\
89 \pm 6.3 \\
934 \pm 3.7\end{array}$ \\
\hline $\begin{array}{l}48 \text { Hr } \\
\text { Withdrawal }\end{array}$ & $\begin{array}{l}\text { Saline } \\
\text { CS } \\
\text { Naloxone } 6 \\
\text { CS + Naloxone } 6\end{array}$ & $\begin{array}{r}5 \\
5 \\
10 \\
10\end{array}$ & $\begin{array}{r}96.1 \pm 2.5 \\
115.7 \pm 7.3 \\
107.3 \pm 4.8 \\
95.1 \pm 8.4\end{array}$ \\
\hline
\end{tabular}

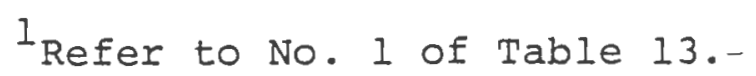

2 Refer to No. 2 of Table 2.

${ }^{3}$ Refer to No. 3 of Table 3 .

${ }^{4}$ Refer to No. 4 of Table 13.

$520 \mathrm{mg} / \mathrm{Kg}$, given intraperitoneally.

$62.5 \mathrm{mg} / \mathrm{Kg}$, given intraperitoneally. 


\section{DISCUSSION}

The major significance of this study is the demonstration that several morphine withdrawal signs can be reduced by environmental stimuli that have been repetitively paired with morphine administration. In this study, rats given an auditory (bel1), gustatory (saccharin) or olfactory (anise oil) stimulus paired with morphine during addiction, exhibited an increase in temperature analogous to the effect of morphine when given the respective stimulus alone during withdrawal.

In addition to temperature, behavioral signs such as shakes, ptosis, writhing and aggression were altered by the olfactory stimulus during withdrawal. The auditory, gustatory, and interoceptive stimuli were found not to significantly alter any of the above-mentioned behavioral signs. Also, two biochemical measures were altered by presentation of anise oil during witharawal: 1) blood glucose, and 2) homovanillic acid.

The following discussion will be divided into four parts. The first part will deal with the auditory, gustatory and interoceptive stimuli. The second part will include evidence establishing the ability of the olfactory stimulus to alter all three types of withdrawal measurements; 1) physical, 2) behavioral and 3) biochemical changes that normally occur following a morphine injection. The third part will deal with the ability of naloxone to reverse the anise 
oil's conditional effects. The last part will deal with the significance of these findings.

Auditory, Gustatory and Interoceptive Stimuli

The addiction schedule used in conditioning morphine's effects to establish the bell as a conditional stimulus, with respect to hypothermia was used unsuccessfully in an attempt to alter other withdrawal signs. It was therefore decided to increase the number of CS-UCS pairings, as other investigators had done, notably Wikler \& Pescor (1967) who paired the CS with morphine for nine weeks. The increased number of pairings, from 30 to 50 were still inadequate since no additional signs were controlled by the bell stimulus.

Since increasing CS-UCS pairings at the dose of $200 \mathrm{mg} /$ $\mathrm{kg} /$ day did not enhance Cs effectiveness with regard to withdrawal signs other than hyperthermia, it was decided to try increasing UCS amplitude. Thus the dose was doubled to 400 $\mathrm{mg} / \mathrm{Kg} / \mathrm{day}$, a dose used in this lab for other types of experiments (Puri \& Lal, 1973; Gianutsos et al., 1974). Again no additional signs were altered at either 30 or 50 pairings. It is important, however, to recognize that in using the four different schedules, the temperature effect was always highly significant following such presentation during withdrawal. The ineffectiveness of the bell to alter other signs beside temperature may have been due to a number of factors which were not tested or tested but not exhaustively analyzed. One possibility may be that even more than 50 pairings may 
be required to be able to bring other withdrawal signs under stimulus control. Goldberg (1971) and Lynch et al. (1973) have shown that stimulus control is indeed dependent upon the number of CS-UCS pairings. Another possible parameter which may have contributed is the length of bell presentation for each trial. This looks especially important when one considers CS strength and CS-UCS optimal interval. In addition, the fact that latter experiments using an olfactory stimulus required the CS to be presented for a time period greater than two minutes lends support to this explanation. Along with the above-mentioned classical conditioning variables is motivation. Once considered only a parameter in instrumental conditioning, it is now known to play a major role in classical conditioning (Beecroft, 1966). Wikler \& Pescor (1967) conditioned their animals by presenting the morphine only once daily, thus assuring that their rats were well into withdrawal.

Another area, separate from addiction procedures, which may have limited conditionability consists of the signs that were monitored. This problem of measuring withdrawal signs has caused a number of labs to measure only one sign (body weight (Kumar, 1972), or to rate a combination of selected signs following antagonist treatment (Wei, 1973)). The concern of this investigation was not to become too restrictive in the signs measured since it was felt that the more signs that could be shown to change following stimulus presentation the better the opportunity would be to show quantiative differences between different types of stimuli. 
The behavioral and physical signs selected were easily measurable; however, many other signs exist for rats going through morphine withdrawal: salivation, rhinorrhea, restlessness, altered food and water consumption (Watanabe, 1971 ; Martin et al., 1963_. Since it would not be practical to monitor all the different signs, those that could be measured with ease and reliability were chosen. All of these variables must be considered in evaluating not only the auditory stimulus, but the other stimuli to be mentioned.

The use of a gustatory stimulus in morphine conditioning experiments has been used by others (Wikler \& Pescor, 1967); Kumar \& Stolerman, 1972); but, not in the same manner it was used in this study.

Saccharine was chosen as a gustatory stimulus because rats have been shown to drink very large amounts when given the opportunity and show preference for it over plain water. The results, however, did not bear out saccharine as a good choice, or that gustatory stimuli in general can serve as CS's. Again, the only sign alterable was temperature and the effect was only about $25 \%$ that of the auditory stimulus, possibly suggesting it was even weaker than the bell. However, many factors may have been involved in the ineffectiveness of saccharine's ability to become a strong conditional stimulus. One reason briefly, alluded to above was the selection of an appropriate gustatory stimulus. A bitter substance may have been a better choice. Or possibly a 
different concentration of saccharine may have increased its effectiveness, since it has been shown that there is a relationship between concentration and the rat's desire for the substance. Also, as was mentioned for the auditory stimulus, the schedule of addiction and the number of pairings may not have been enough to allow for saccharine to control additional morphine-like effects when presented during withdrawal.

In addition to schedule of addiction, the CS-UCS interval was very important in this experiment and may indeed have been the biggest reason for saccharine failure to elicit morphine-like effects. The saccharine was infused for only 45 seconds because the withdrawn animal became very restless; since the only restraint was the experimenter's hand, he became difficult to manage. Thus the stimulus was very short and time of UCS onset was longer than might be desired. Also, the problems of motivation and signs monitored apply to the gustatory experiment.

The third type of stimulus, interoceptive, was shown to be even less effective than either auditory or gustatory stimuli. Not even temperature was increased by any of the drugs (apomorphine, alcohol or pentobarbital) paired with morphine, when later given by themselves during withdrawal. The use of a drug as a CS coupled with a UCS (drug) has not been shown to be effective (Lynch, et al., 1973) but few experimenters have tried such a combination. 
The selection of apomorphine, alcohol and pentobarbital was based on their distinctive ability to be discriminated by the rat as being different from the UCS and thus a foundation for a CS-UCS pairing (Overton, 1972). However, combining drug effects can cause a number of problems, especially with the drugs selected. Apomorphine, it is thought, works opposite to morphine in the dopaminergic system (Kaariainen and Ahtee, 1976) and even at the dose given may cause an undesirable interaction apart from the gastrointestinal disturbances. This, unfortunately, was the case. Withdrawal signs were fewer in number without presentation of the CS and apomorphine affected temperature by itself in withdrawn animals, when it was not paired during addiction, thus confounding any temperature data that may have been obtained. Since the experiment was completed it has been shown that very small doses $(0.16 \mathrm{mg} / \mathrm{Kg})$ of apomorphine show major endocrine effects in withdrawn rats (Lal et al., 1976) thus suggesting that reducing the dose would be imperative so as not to confound the withdrawal signs by effects of apomorphine itself.

Alcohol and pentobarbital at the doses used also had effects of their own which confounded the withdrawal signs monitored. Unfortunately, no data existed prior to these attempts at observing the interaction of acute or chronic morphine with the drugs selected and what may happen during withdrawal when only pentobarbital or alcohol is administered alone. One problem that occurred with the other 
stimuli which was circumvented by the drug stimuli was duration of $C S$ and CS-UCS interval. The drugs were given so as at least a 15-min overlap between CS-UCS existed, so as to insure that the stimulus was present when morphine began to have an effect.

From the data where an interoceptive stimulus was paired with morphine it appears that this type of conditiioning because of drug variables is probably the most difficult (dose duration of action, interaction). This does not mean that such an attempt should not be considered, but a number of preliminary experiments should be done prior to selection of a substance to be used (i.e., effect of substance on nonpaired morphine-withdrawn animals.

Use of an Olfactory Stimulus to Alter Morphine Withdrawal Signs in Addicted Rats

The following section contains evidence that a conditional stimulus, anise odor, is able to elicit effects during withdrawal which normally are produced only by morphine.

In animals addicted to anise-oil-morphine:

1. To be effective as a CS, oil of anise must be presented for more than 2 min but not to exceed $30 \mathrm{~min}$ to $\mathrm{CS}-$ morphine-paired animals during withdrawal.

2. In the presence of the CS, 24 and 48 hours after the last Cs-morphine pairing, the rats showed respectively a $30 \%$ and $35 \%$ reduction in wet shakes. If no CS was presented the 
conditioned animals exhibited a $10 \%$ increase in shakes at 24 and 48 hrs of withdrawal. If the CS was randomly presented to the rats during addiction and then presented anise oil during withdrawal, this group showed a $10 \%$ increase in shakes at $24 \mathrm{hr}$ and $20 \%$ increase at 48 hr of withdrawal.

3. In the presence of the CS, 24 and 48 hr after the last CS-morphine pairing, the rats showed a significant increase in rectal temperature. If no CS was presented the conditioned animals showed no change in temperature comparing the temperature before and after observation. The group of random oil of anise-morphine when given the CS also showed no change in rectal temperature.

4. In the presence of the CS, 24 and 48 hours after the last CS-morphine pairing, the rats showed a significant reduction in writhing and an increase in ptosis time at 24 and $48 \mathrm{hr}$ of withdrawal. Conditioned rats not receiving the CS showed an increase in writing at 24 hours and no change at 48 hours. Ptosis time increased for the conditioned animals not getting the CS but not nearly to the extent of the conditioned animals. The random Cs-morphine group when given the cs during withdrawal exhibited increased writhing at 24 and 48 hours and their ptosis time increased but again not nearly as much as the conditioned animals following Cs treatment.

5. In the presence of the CS, 48 hr after the last CS-morphine pairing, the rats exhibited a significant reduction in aggressive behavior. If no CS was presented, grouped 
conditioned animals fought vigorously. Addicted animals not given the CS during addiction and given the Cs during withdrawal, fought when grouped during withdrawal as did the random cs-morphine group.

These data suggest the following:

1. The anise oil, when paired with morphine during addiction, was able to effectively alter a number of withdrawal signs. Thus the anise oil had acquired conditional properties.

2. The conditional effect could be seen for at least $48 \mathrm{hr}$ after the last CS-UCS pairing.

3. Anise oil when not systematically paired with morphine had no significant effect when presented during withdrawal on any signs monitored.

4. Anise oil presentation was adequate to reduce aggressive behavior of conditioned rats, thus giving strong support for an overall reduction of unstability due to narcotic withdrawal.

Behavorially the work using oil of anise (olfaction) has a number of very important implications. The first being, that smell seems to play a more important role in conditioning of morphine's effects. Even though the bell was somewhat effective in mimicking an action of morphine, only olfaction was able to alter temperature, shakes, writhing, and aggression. This becomes even more important as the first systematic attempt at human conditioning [O'Brien, 1976) 
used an uaidoty tone and olfaction (oil of peppermint) as a compound CS, thus using the best two senses as found in this study .

The o'Brien study was successful in conditioning withdrawal signs by pairing the compound CS with naloxone and after a number of days giving the cs alone, thus inducing withdrawal without the antagonist. Five of the eight subjects in the study showed that the auditory and olfactory stimuli had acquired conditional properties.

In the present study it is difficult to assess other factors which may cause the procedure used for conditioning to involve a compound conditional stimulus. However, the strongest factor in the chain of events must be the anise oil as only the experimental group showed conditioning of morphine's effects.

In addition to the physical and psychological changés controlled by anise oil, HVA was observed to be brought under stimulus control. Only one other lab has reported such a find (Perez-Cruet; 1976) and he brought dopamine (DA) metaboIism under stimulus control using a buzzer as the CS and methadone as a UCS. The present study shows the CS to increase DA metabolism, thus increasing HVA formation at 24 and 72 hr following the last CS-morphine pairing.

The increase in HVA levels following CS presentation would not seem to be due to chance since conditioned animals not receiving the CS showed no changes in DA metabolism. It is also as unlikely that the changes observed are due to 
stress as all controls were put through the same procedure as the experimental group except they did not get the CS. Since the classical conditioning paradigm utilized in this study has been used to establish drug conditioning with fairly good success, it is more likely to assume that the changes in HVA levels associated with the CS (olfactory-oil of anise) are the result of drug conditioning and this change can be considered as a conditional reflex of $D A$ metabolism.

The ability to alter a transmitter of the brain should open new thinking into the complicated function of neurotransmitters in the brain as the activities of these transmitters are not only affected by direct stimuli, but also by conditioned experiences to which the organism has learned a reflex response. The fact that a transmitter can be brought under stimulus control may alter the thinking of individuals in the learning field who generally assumed that a neurotransmitter's function would be very difficult to alter by a psychological stimulus (Perez-Cruet, 1976). There are a number of good reasons to support the above statement: 1) neurotransmitter functions depend on enzymes which must travel from the cell body down the neuron, the process takes approximately 2.5 days; and 2) unless neurotransmitter functions are measured within specific neuronal pathways it will be very hard to determine what kind of impact the stimulus may have on neurotransmitter function. Also, it must be remembered that only one metabolite in one area was measured. Other 
transmitters such as, acetylcholine, serotonin or norepinephrine may be altered as well as other areas may be involved such as hypothalamus (endocrine and temperature) or amygdola (aggression). Many more studies will be required to elucidate the activity of DA as being the only transmitter which can be conditioned or that others may be brought under stimulus control. It is most likely that a number of transmitters are involved in the conditioned response and not just DA.

Even though the changes in HVA levels has been defined as a conditional phenomenon, in terms of neurotransmitter function, this change may represent a much more complex activity because the stimulus-reflex association most likely occurs cortically, as well as striatally. Also, the drug may act at a receptor whereas the stimulus may cause something to be released which will then affect the receptor.

Considering all of the many possibilities discussed above in explaining how the conditional stimulus affects neurotransmitter function the fact remains that the process does occur with pairing an auditory stimulus with methadone (Ferez-Cruet, 1976) and pairing an olfactory stimulus with morphine. Thus it seems that the brain functions can be conditioned like those of other visceral organs.

A second biochemical change was brought under stimulus control, blood glucose. The changes due to cs presentation could be seen at 24 and $48 \mathrm{hr}$ withdrawal in animals which had 50 pairings of CS-morphine. This conditional increase is 
difficult to explain as it has been shown by Sable-Amplis (1972) that tolerance develops to the increase in blood glucose levels following morphine administration. Thus after only 3 or 4 injections the injection of morphine and CS are no longer paired with the biochemical change. Thus one explanation for this increase in blood glucose level during withdrawal following CS presentation may be that another system was conditioned and the resultant effect was expressed as increased blood glucose. There is no doubt that the glucose level increased, just that the system or systems causing this change remain to be elucidated.

Use of Naloxone to Reverse the Effects of a CS

The ability of naloxone to block the CS effects on temperature and shakes in conditioned animals as it does in morphine addicted animals given morphine has some very important implications. Since an opiate receptor was found by Pert and snyder (1973) and a number of substances isolated which may affect this receptor lone endorphin associated with a reduction in pain) these bits of information may indeed be valuable in explaining how naloxone blocks a conditional stimulus from mimicking morphine's effects. Given that an endorphin exists (Goldstein, 1976; Hughes et al., 1975; Terenius and Wahistrom, 1975; Simantov and Snyder, 1976), then the CS may be activating this substance which in turn acts on the opiate receptor and the resultant behaviorial 
changes which were previously attributed to morphine, now occur following CS presentation.

To explain in detail the last statement it is important to understand how endorphin may be working. Normally, enkephalin may be assumed to control certain inhibitory mechanisms determining the level of neurotransmitter release. If an opiate is administered to increase this level of inhibition, to cause analgesia, then the control will be under the exogenous narcotic and not the endogenous enkephalin. A negative feedback may slow down or even stop the synthesis of the endogenous substance now that an exogenous opiate has taken control (Kosterlitz and Hughes, 1975). Now the central nervous system will be completely dependent on the injected narcotic to maintain the inhibitory mechanism.

When the narcotic is withdrawn suddenly, those inhibitory mechanisms become inactive, because what endorphin exists will not be able to stimulate the opiate receptor until the receptors regain their sensitivity or until enough enkephalin can be synthesized or both. Thus the withdrawal syndrome develops which may be attributed to the lack of control of the inhibitory system. Now if the CS were presented to conditioned animals it may cause any one or more of the following :

1) A transient alteration in receptor sensitivity;

release the peptide substance (enkephalin) in large enough quantities to partially alter a number of withdrawal signs, or 3) mobilize morphine which still can be found in tissue to affect opiate receptors. 
The above mentioned phenomenon of the CS altering opiate receptors or releasing enkephalin can be borne out by the fact that naloxone was able to reverse the cs effect as it reverses morphin effects; thus, providing strong indirect evidence for a mechanism of how the CS works. Unfortunately, the attempt to block the CS's effect on blood glucose levels was very confusing, and little can be said. It looked as though naloxone was affecting baseline levels of blood glucose thus making it difficult to interpret the results, But, it must be remembered that the effect seen may not be a direct effect of the CS as hepatic glycogenolysis which occurs following morphine initially disappears after 3-4 injections. Also, glucose metabolism remains difficult to assess even after a month of withdrawal (Sable-Amplis, 1972). Thus the system itself is rather complex and its function not fully understood following narcotic administration.

It does look from Table 16 that the conditioned changes in blood glucose levels were blocked, but further work must be done before such a conclusion can be drawn. A better understanding of glucose metabolism following narcotics is necessary and naloxone's effects on glucose levels of both addicted and naive rats should be studied. Significance of the Findings

Many researchers are approaching conditional aspects of narcotic addiction from the standpoint that human addicts take heroin in order to relieve withdrawal. However, this 
study suggests that neutral stimuli which are paired frequently enough with morphine injections will come to elicit the same or similar physiological reactions as the drugs themselves. For example, when the addict sees a syringe and any other environmental factors associated with "shooting-up," it will begin to elicit physiological reactions to morphine before it is ingested. This can be seen more vividly by "needle freaks" who will stick themselves and shoot anything in order to postpone the onset of withdrawal.

What may be happening in the above situation of the "needle freak" is that he is able to release the morphine-like substance and relieve (temporarily) some withdrawal signs by sticking himself. The release of enkephalin may be exactly what the olfactory $C S$ is releasing, thus in part an animal analog of activation has been creation. Thus if an animal analog of narcotic addiction has been developed the next and probably most important phenomenon can be observed - extinction. If the effects of a narcotic are really conditioned, then the resistance to extinction should be very high. Also, this opens the possibility of injecting enkephalin into the conditioned animals and see if enkephalin without the CS can reduce parts of the withdrawal syndrome similar to the CS. Also, since the areas which contain opiate receptors have been localized, naloxone could be injected into different areas to see which one(s) must be blocked in order to prevent the CS from working. 
This study has provided additional groundwork for future work by: 1) neurochemists to determine if the condtioning of other neurotransmitter systems will be useful in establishing whether there is a general pattern of conditioned neurotransmitter functions in brain or specific conditioning of monoaminergic functions; 2) physiological psychologists to determine which area of the brain has the major responsibility for narcotic conditioning behavior; 3) psychiatrist to develop experiments utilizing human subjects to see if the major concern of the addict is to prevent withdrawal or the conditioning is of the drug effects as eluted to above; and 4) sociologist to better characterize the environmental cues that may be best associated with narcotic administration given that a better understanding of the conditional phenomenon is forthcoming.

This study also supports the use of narcotic antagonists in treatment of narcotic addicts. The problem that arises now is what part of drug taking behavior can be classified as operant and what part as classical conditioning. Thus all that really can be said from this study is that a narcotic antagonist would be useful in treatment of human addicts, as seen from the animal analog, but the extent of its usefulness may be just of limited value.

Many more systematic studies must be done to evaluate the components of classical conditioning such as CS-UCS interval, motivation, acquisition and extinction in arug conditioning experiments. 
CONCLUS IONS

1) The conditional stimulus found best in development of an animal analog of narcotic addiction was oil of anise (olfactory) (see Table I7).

2) The olfactory conditional stinulus was able to alter both physical and psychological temperature withdrawal signs which include: temperature (similar to an auditory stimulus (bell)), shakes, writhing and aggression.

3) The olfactory conditional stimulus was able to alter two biochemical systems: I) dopamine metabolism (HVA levels) and 2) blood glucose levels similar to the action of morphine.

4) Naloxone was able to block both physical and behavorial properties of the CS supporting the possibility that the CS may work by releasing an endogenous morphine-like substance. 
Table 17

Summary of Conditioning Experiments

\begin{tabular}{|c|c|c|c|c|c|c|c|c|}
\hline \multirow{2}{*}{ Stimulus } & \multicolumn{8}{|c|}{ Signs Measured } \\
\hline & Temperature & Shakes & Ptosis & Piloerection & Writhing & Aggression & $\mathrm{BG}^{2}$ & HVA \\
\hline Morphine & $+H$ & $++1+$ & $+1+$ & $++H$ & $+1+$ & $+1+$ & $H$ & +++ \\
\hline O11 Anise & $H$ & + & 0 & + & ++ & $H$ & $H$ & $H$ \\
\hline Be11 - & $H$ & 0 & + & 0 & 0 & - & - & - \\
\hline Saccharin & + & 0 & 0 & 0 & 0 & - & - & - \\
\hline Pentobarbital & 0 & 0 & 0 & 0 & 0 & - & - & - \\
\hline Apomorphine & 0 & 0 & 0 & 0 & 0 & - & - & - \\
\hline Alcohol & 0 & 0 & 0 & 0 & 0 & - & - & - \\
\hline
\end{tabular}

$1_{\text {Withdrawal signs measured at } 24,48,72 \text { hr withdrawal }}$

2 Blood g1ucose leve1

${ }^{3}$ Homovanillic acid level

$\left(\right.$ Note $:+=$ small effect, $H=$ medium effect, $H_{+}=1$ arge effect, $H=$ very potent effect, $0=$ no effect, - not measured.) 


\section{REFERENCES}

Ahtee, I. and Kaariainen, I.: The effect of narcotic analgesics on the homovanillic acid content of rat nucleus caudatus. Eur. J. Pharmacol. 22:206-208, 1973.

Alvarez-Buylla, R., Carrasco-zanini, J.: A condition reflex which reproduces the hypoglycemic effect of insulin. Acta Physiol. Lat Am 10:153-158, 1960.

Anand, B.K., Chhina, G.S., Sharma, K.N., et al.: Activity of single neurons in the hypothalamic feeding centers: effects of glucose. Am. J. Physiol. 207:1146-1154, 1964.

Anden, N.E., Roose, B.E., and Werdinius, B.: On the occurrence of HVA in brain and CSF and its determination by a fluorometric method. Life Sci. $\underline{7}, 448-458,1962$.

Araki, T.: Uber die Bildung von Milchsaure und glucose in organismus bei sauerstoffmangel. Uber die workung von morphinium amphritrit, cocain. Hoppe seyler's Z . Phisol. Chem. 15:546-561, 1891.

Ausubel, D.: Drug addiction: physiological, psychological and sociological aspects. Random House, N.Y. 1963.

Barthelmai, $W$. and R. Czak: Enzymatische bestimmunger der glucose in blut, uguor and harn. Klin Wochencher. $\underline{40}: 585-90,1962$.

Balagura, S., Kanner, M.: Hypothalamic sensitivity to 2-deoxyD-glucose and glucose: effects on feeding behavior. Physiol Behav. 7:251-255, 1971.

Beach, H.D.: Morphine addiction in rats. Can. J. Psychol., 11:104-112, 1957 .

Beecroft,R:Classical conditioning. Psychonomic Press, Houston, Texas, 1966.

Belluzzi, J.D., Grant, N., Garsky, V., Sarantakis, D., ' Wise, C.D. and Stein, I.: Analgesia induced in vivo by central administration of enkephalin in rat. Nature 260:625-26, 1976.

Blumberg, H. and Dayton, H.: Naloxone and related compounds. In Agonist and Antagonist actions of narcotic analgesic drugs. Ed. by H. Kosterlitz, H. Collier and J. Villareal, pp. 110-19, University Press, Baltimore, 1973. 
Borison, H.I., Fishburn, B.R., Bhide, N.K., and McCarthy, I.E.: Morphine-induced hyperglycemia in the cat. J. Pharmac. Exp. Ther. 138:229-235, 1962 .

Brown, K.A., Melzack, R.: Effects of glucose on multi-unit activity in the hypothalmus. Exp. Neurol. 24:363-373, 1969 .

Bykov, K.M.: The Cerebral cortex and the Internal organs. Trans. by W.H. Gant. Chemical Publishing Co., New York, 1957.

Chambers, R.M.: Effects of intravenous glucose injections on learning, general activity, and hunger drive. J. Comp. Physiol. Psychol. 49:558-564, 1956.

Chambers, R.M.: Some physiological bases for reinforcing properties of reward injections. J. Comp. Physiol. Psychol. 49:565-568, 1956.

Cofer, C. and Appley, M.: Motivation: Theory and Research. John Wiley and Sons, N.Y. 1964.

Collins, K.H. and Tatum, A.I.: A conditioned reflex established by chronic morphine poisoning. Am. J. Physiology 74: $15-16,1925$.

Crisler, G.: The effect of withdrawal of water on the salivary conditioned reflex induced by morphine. Am. J. Physiol. 85:324-331, 1928 .

Crowder, W., Smith, S., Davis, W.M., Noel, J. and Coussens, W.: Effect of morphine dose size on the conditioned reinforcing potency of stimuli paired with morphine. Psych. Record 22:441-48, 1972 .

Dey, P.K., Feldberg, W. and Wendland, S.: Comparison of the hyperglycaemic effect of adrenaline and morphine introduced into the liquor space. J. Physiol. 246: 213-228, 1975 .

Drawbaugh, R. and Lal, H.: Reversal by narcotic antagonist of a narcotic action elicited by a conditional stimulus. Nature 247:65-67, 1974 .

Drawbaugh, R., and Lal, H.: Effect of pharmacologic interference with various neuropathways on blockade of morphine-withdrawal hypothermia by morphine and by conditional stimulus. Neuropharmacol. 15, 375-378, 1976. 
Faust, E.S. Veber die ursachen der gewohrung an morphin. In Spraggs, S.D.S., Trans. Morphine addiction in chimpanzees. Comp. Psychol. Mong., 15: Vol 7, 1940.

Feldberg, W., and Gupta, K.P.: Morphine hyperglcaemia. J. Physiol. 238:487-502, 1974 .

Feldberg, W. and Shaligram, S.V.: The hyperglycaemic effect of morphine. Brit. J. Pharmacol. 46:602-618, 1972.

Fukui, K. and Takagi, H.: Effect of morphine on the cerebral contents of metabolites of dopamine in normal and tolerant mice: its possible relation to analgesic action. Br. J. Pharmacol. 44:45-51, 1972.

Gianutsos, G., Hynes, M., Puri, S., Drawbaugh, R. and Lal, H.: Effect of apomorphine and nigrostriatal lesions on aggression and striatal dopamine turnover during morphine withdrawal: evidence for dopaminergic supersensitivity in protracted abstinence. Psychopharmaologia 34: 37-44, 1974 .

Goldberg, S.: Nalorphiric: conditioning of drug effects on operant performance. In Stimulus Properties of Drugs. Ed. by $T$. Thompson and R. Pickens, pp. 51-72, AppletonCentury-Crofts, New York, 1971.

Goldberg, S.R. and Schuster, C.R.: Conditioned suppression by a stimulus associated with nalorphine in morphinedependent monkeys. J. Exp. Anal. Behav. 10:235-42, 1967.

Goldberg, S. and Schuster, C.: Conditioned nalorphine induced abstinence changes: persistence in post-morphine dependent monkeys. J. Exp. Analysis Behav. 14:33-46, 1970 .

Goldberg, S.R., woods, J.H., and Schuster, C.R.: Nalorphineinduced changes in morphine self-administration in rhesus monkeys. J. Pharmacol. Exp. Ther. 176:464-471, 1971.

Goldstein, A.: Biostatistics. MacMillan Co., New York, 1964.

Goldstein, A.: Opioid peptides (Endorphins) in pituitary and brain. Science 193, 1081-1086, 1976.

Hughes, J., Smith, T., Morgan, B., and Fothergill, L.: Purification and properties of enkephalin. The possible endogenous ligand for the morphine receptor. Life Sci. 16:1753-1758, 1975 . 
Hutton, R.A., Woods, S.C., Makovs, W.: Conditioned hypoglycemia: pseudoconditioning controls. J. Comp. Physiol. Psychol. 71:198-201, 1970.

Jones, B.E., and Prada, J.A.: Relapse to morphine use in dog. Psychopharmacologia 30, 1-12, 1973.

Kaariainen, I. and Ahtee, I.: Effect of narcotic analgesics on the striatal homovanillic acid content in mice; relation to antinoceptive effect. Med. Biol. 54, $56-61,1976$.

King, C.D., Masserano, J.M., Santos, N.H., Codd, E.E., and Byrne, W.L.:Behavorial effects of partially purified mouse endorphin. Fed. Proc., 1976.

Kleitman, N.: The onset of sleep during morphine-conditioned salivation. Am. J. Physiol. 90:411, 1929.

Kleitman, N., and Crisku, G.: A quantitative study of a salivary-conditioned reflex. Am. J. Physiology 79: $571-614,1927$.

Kolb, L.: Drug addiction: A medical problem. C. Thomas, Springfield, Illinois, 1962 .

Kosterlitz, H., Hughes, H.W. Some thoughts on the significance of enkephalin, the endogenous ligand. Life Sci. 17: 91-96, 1975 .

Kumar, R.: Morphine dependence in rats: secondary reinforcement from environmental stimuli. Psychopharmacologia 25: $332-38,1972$.

Kumar, R., and Stolerman, I.: Resumption of morphine selfadministration by ex-addict rats. J. Comp. Physiol. Psych. 3 : 457-65, 1972 .

Kuschinsky, K. and Homyliewicz, O.: Morphine catelepsy in the rat: relation to striatal dopamine metabolism. Eur. J. Pharmacol. 19:119-122, 1972.

Lal, H., Brown, W., Drawbaugh, R., Hynes, M. and Brown, G.: Enhanced prolactin inhibition following chronic treatment with haloperidol and morphine. Life science, 1977.

Lal, H., Miksic, S., Drawbaugh, R., Newman, R., and Smith, N.: Alleviation of narcotic withdrawal syndrome by conditional stimuli. Pavlovian J. Biol. Res. 1977 (in press) 
Leites, S.M., Pavlov, G.T.: Conditioned reaction to the sugar reducing funtion of insulin in experimental diabetes. Zh. Vyssh. Nervn. Deiafel 4 : 234, 1954 .

Levine, D.G.: "Needle freaks": compulsive self-injection by drug users. Am. J. Psychiatry 131:297-300, 1974.

Lichko, A.E.: Conditioned reflex hypoglycemia in man. Zh. Vyssh. Nervn. Deiatel 9:823-829, 1959 (and in Pav J

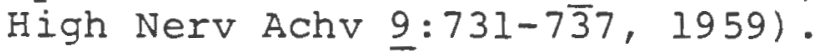

Lomax, P.: Drugs and body temperature. Rev. Neurobiol. 12: $1-43,1970$.

Irnch, J.J., Fertziger, A.P., Teitelbaum, N.A., Cullen, J.W., and Gantt, W.H. Pavlovian conditioning of drug reactions: some implications for problems of drug addiction. Condit. Reflex 8:211-223, 1973.

Lynch, J.J., Stein, E.A., Fertziger, A.P. An analysis of 70 years of morphine classical conditioning: Implications for clinical treatment of narcotic addiction. J. of Nervous \& Mental Disease, 163:47-58, 1976.

Martin, W.R., Wikler, A., Eades, C. and Pescor, F.: Tolerance to and physical dependence on morphine in rats. Psychopharmacologia 4:247-260, 1963 .

Miselis, R.R., Epstein, A.N.: Feeding induced by 2-deoxy-Dglucose injections into the lateral ventricles of the rat. Physiologist 13:262, 1970.

Muller, E.E., Frohman, L.A., Cocchi, D.: Drug control of hyperglycemia and inhibition of insulin secretion due mainly to centrally administered 2-deoxy-D-glucose. Am. J. Physio1.224:1210-1217, 1973.

Myers, R.: General laboratory procedures. In Methods in Psychobiology l; ed. by R. Myers, Academic Press, New York, 1971 .

O'Brien, C.P.: Experimental analysis of conditioning factors in human narcotic addiction. Pharmacol Rev. 27: $533-543,1976$.

O'Brien, C.P., O'Brien, T.J., Mintz, J. and Brady, J.P.: Classically conditioned abstinence symptoms in human subjects. Problems of Drug Depend: 320-330, 1975.

Oomura, Y., Kimura, K., Ooyama, H., et al.: Reciprocal activities of the ventromedial and lateral hypothalmic areas of cats. Science 143:484-485, 1964. 
Oomura, Y., Ono, T., Ooyama, H., et al.: Glucose an osmosensitive neurons of the rat hypothalmus. Nature 222: $282-284,1969$.

Overton, D.: State dependent learning in stimulus properties of drugs, ed. by Thompson and Pickens, Appleton-Century Crofts, New York (p 87-110), 1971.

Parker, L., Failor, A. and weidman, K.: Conditioned preferences in the rat with an unnatural need state and morphine withdrawal. J. Comp. Physiol. Psychol.: 82: $294-300,1973$.

Pavlov, I.P.: In Anrep, G., Ed. and Trans. Conditioned Reflexes. Oxford University Press, London, 1927.

Perez-Cruet, J.: Conditioning of striatal dopamine metabolism with methadone, morphine and bulbocaprine as an unconditioned stimulus. Pavlovian J. Biol. Res. 1977 (in press).

Perez-Cruet, J.: Conditional reflex changes in dopamine metabolism induced by methadone as an unconditional stimulus.

In: Drug Addiction ed. by Lal and Singh. (1974), pp. 249.

Pierce, I.H. and Plant, O.H.: Studies in chronic morphine poisoning in dogs. III. Blood sugar during tolerance and withdrawal. J. Pharmacol. Exp. Ther, 371-385, 1928.

Pert, C.B. and Snyder, S.H.: Opiate receptor: demonstration in nervous tissue. Science 179:1011-1014, 1973.

Puri, S. and Lal, H.: Effect of dopaminergic stimulation or blockade on morphine-withdrawal aggression. Psychopharmacologia 32:113-120, 1973.

Roffman, M. and Lal, H.: Stimulus control of hexabarbital narcosis and metabolism in mice. J. Pharmacol. Exp. Ther: 191: 358-69, 1974 .

Roffman, M., Reddy, C. and Lal, H.: Control of morphine withdrawal hypothermia by conditional stimuli. Psychopharmacologia 29:197-201, 1973.

Ross, E.L.: Blood dextrose as affected by morphine and morphine with ether anesthesia. J. Biol. Chem. 34:335-342, 1918.

Sakata, K. Hayano, S., Sloviter, H.A.: Effect on blood glucose concentration of changes in availability of glucose to the brain. Am. J. Physiol. 204:1127-1132, 1963. 
Sable-Amplis, R.: Evolution de divers effects de la morphine en relation avec la tolerance et la dependance physique. Doctoral Dissertation. I'Universite Paul Sabatier de Toulouse, 1972.

Sasame, H.A., Perez-Cruet, J., DiChiara, B., Tagliamonte, G., Tagliamonte, P. and Gessa, G.L.: Evidence that methadone blocks dopamine receptors in the brain. J. Neurochem 19, 1953-57, 1972.

Savchenko, V.A.: Conditioned reflex hypoglycemia, glucosuria, and hyperglycemia. Bull. Biol. Med. Exp. 9:361-363, 1940 .

Shannon, J.A., Tennant, F., and Lobue, A.J.: Medicinal use of hypodermic needles in an addict patient population. Dis. Nervous System 37:443-44, 1976.

Simantov, R., Snyder, S.H.: Isolation and structure identification of a morphine-like peptide "Enkephalin" in bovine brain. Life Sci. 18:781-788, 1976.

Spragg, S.D.S.: Morphine addiction in chimpanzees. Comp. Psychol. Monogr., 15: No. 7, 1940.

Szabo, O., Szabo, A.J.: Evidence for an insulin-sensitive receptor in the central nervous system. Am. J. Physiol. 223: $1349-1353,1972$.

Terenius, I., Wahlstrom, A.: Morphine-like ligand for opiate receptors in human CSF. Life Sci. 16:1759-1764, 1975.

Thompson, T., and Ostlund, W.: Susceptibility to readdiction as a function of the addiction and withdrawal environments. J. Comp. Physiol. Psychol., 60:388-392, 1965.

Thompson, T. and Pickens, R.: Drug self-administration and conditioning. In Scientific Basis of Drug Dependence. Ed. by H. Steinberg, pp. 271-80, Grune \& Stratton Inc., N.Y., 1969 .

Thompson, J. and Pickens, R.: Interoceptive stimulus control of behavior. In: Stimulus properties of Drugs ed. by Thompson and Pickens. Appleton-Century-Crofts, New York (1971), pp 3-12.

Trost, R.C.: Differential classical conditioning of abstinence syndrome in morphine-dependent rats. Psychopharmacologia $30: 153-161,1973$. 
Walters, J.R. and Roth, R.A.: Effect of -hydroxybutyrate on dopamine metabolites in rat striatum. Biochem.

Pharmacol. 21:2111-2115, 1972 .

Watanabe, H.: The development of tolerance to and of physical dependence on morphine following intraventricular injection in the rat. Japan J. Pharmacol. 21:383-391, 1971.

Weeks, J. and Collins, R.: Factors affecting voluntary morphine intake in self-maintained addicted rats. Psychopharmacologia $6: 267-79,1964$.

Wei, E.: Assessment of precipitated abstinence in morphine dependent rats. Psychopharmacologia 28:35-44, 1973.

Wikler, A.: Some implications of conditioning theory for problems of drug abuse. Behav. Sci. 16:92-97, 1971.

Wikler, A.: Recent progress in research on the neurophysiologic basis of morphine addiction. Am. J. Psychiatry, 105:329-338, 1948 .

Wikler, A.: Some implications of conditioning theory for problems of drug abuse. Behav. Science 16:92-97, 1971.

Wikler, A. and Pescor, F.T.: Persistence of "Relapse tendencies" of rats previously made physically dependent on morphine. Psychopharmacologia 16:375-384, 1970 .

Wikler, A. and Pescor, F.T.: Classical conditional of a morphine abstinence phenomenon reinforcement of opioiddrinking behavior and 'relapse' in morphine addicted rats. Psychopharmacologia 10:255-284, 1967.

Woods, S.C., Makous, w., Hutton, R.A.: A new technique for conditioned hypoglycemia. Psychon Sci. 10:389-390, 1968.

Woods, S.C., Makous, W., Hutton, R.A.: Temporal parameters of conditioned hypoglycemia. J. Comp. Physiol. Psychol. 69: $301-307,1969$.

Woods, S.C., Shogren, R.E.: Glycemic responses allowing conditioning with different doses of insulin in rats.

J. Comp. Physiol. Psychol. 81:220-225, 1972.

Zakharov, S.V.: On conditional-reflex insulin hypoglycemia. Zh vyssh nervn deiatel 10:280-284, 1960 (and in Pav J

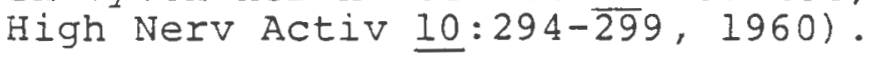


